Technical Report

December 1995

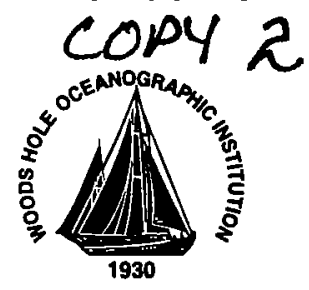

\title{
Cyclic Fatigue Testing of Surface Mooring Hardware for the Arabian Sea Mixed Layer Dynamics Experiment
}

by

Richard P. Trask

Robert A. Weller
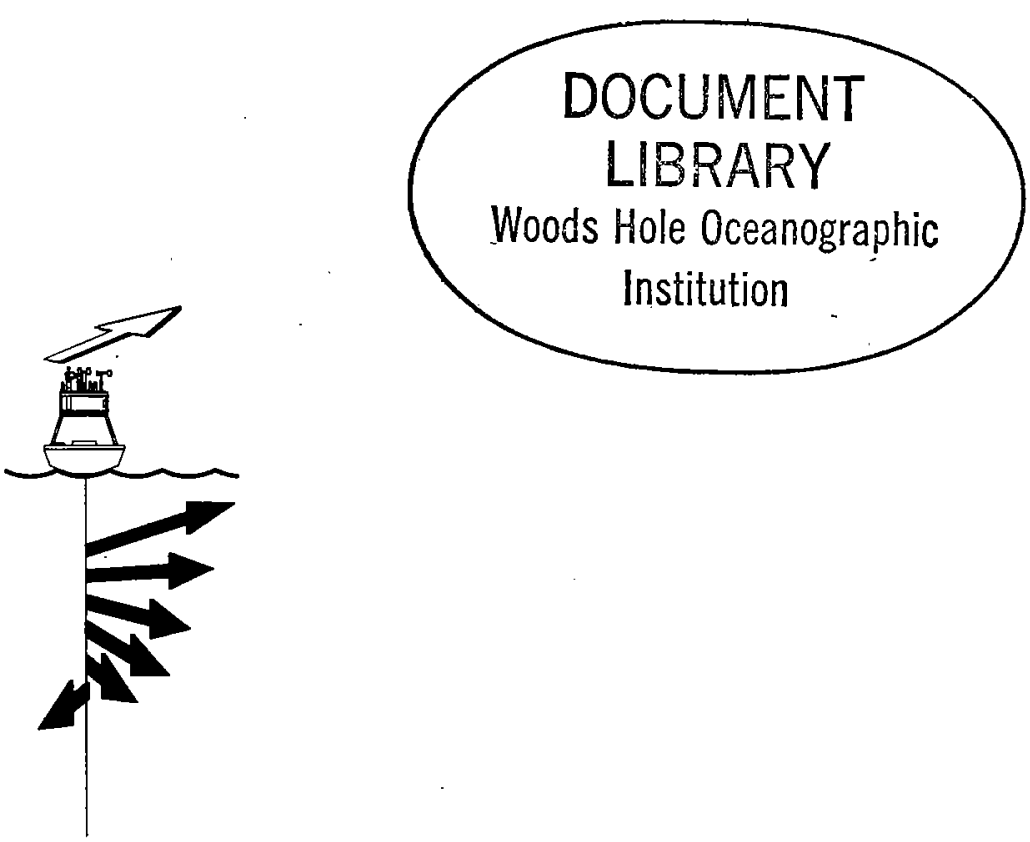

Upper Ocean Processes Group

Woods Hole Oceanographic Institution

Woods Hole, Massachusetts 02543 U.S.A.

UOP Technical Report 95-5 


\section{WHOI-95-16 \\ UOP 95-05}

Cyclic Fatigue Testing of Surface Mooring Hardware for the Arabian Sea Mixed Layer Dynamics Experiment

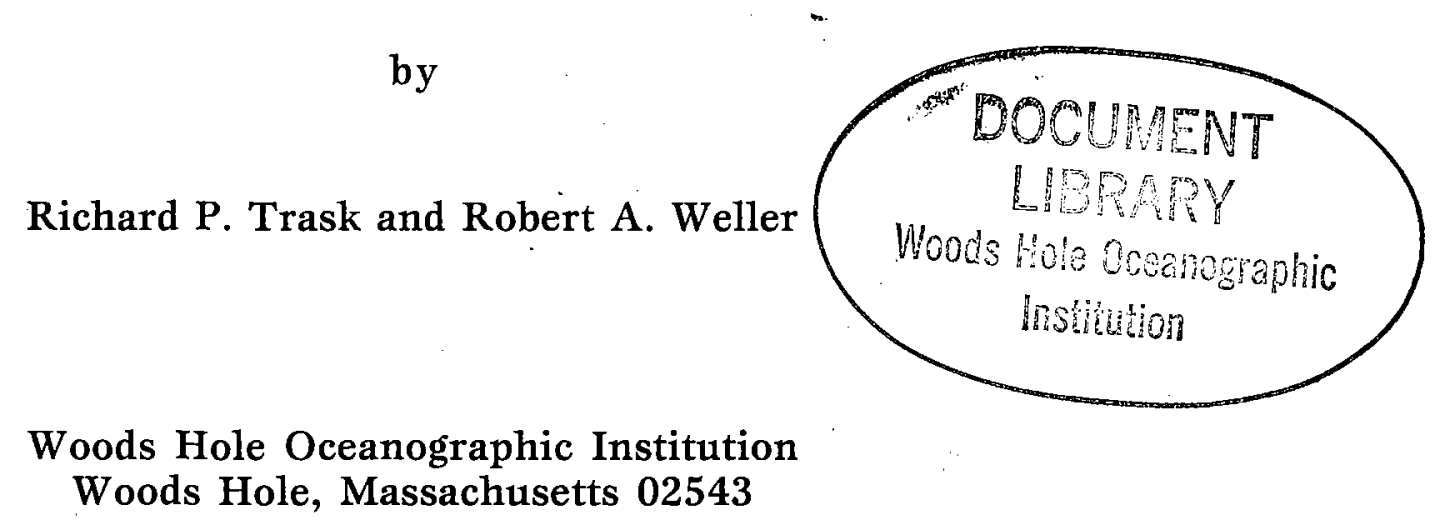

December 1995

\section{Technical Report}

Funding was provided by the Office of Naval Research through

Grant No. N00014-94-1-0161.

Reproduction in whole or in part is permitted for any purpose of the United States Government. This report should be cited as Woods Hole Oceanog. Inst. Tech. Rept., WHOI-95-16.

Approved for public release; distribution unlimited.

Approved for Distribution:
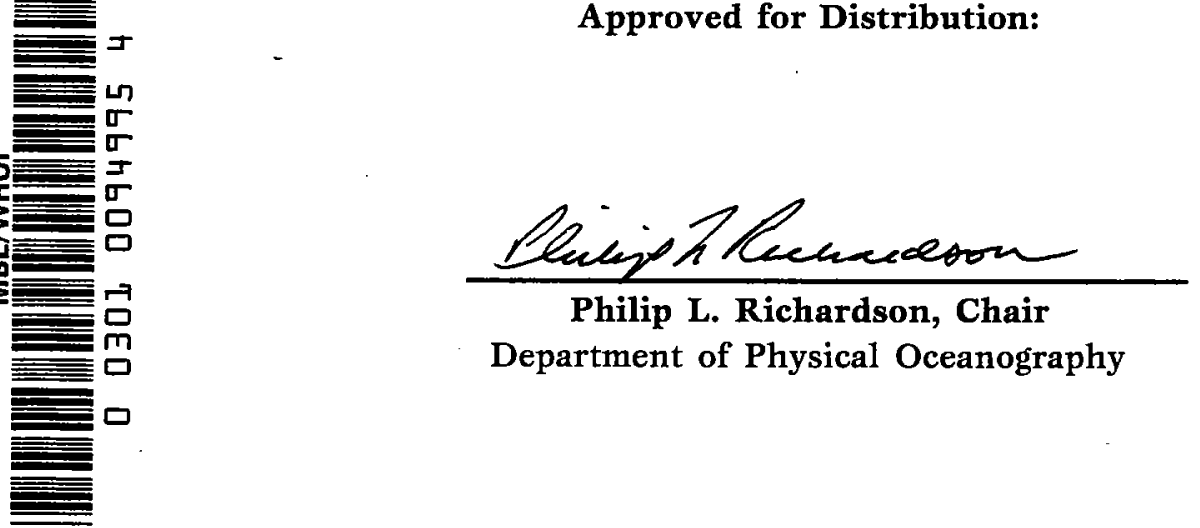

Philip L. Richardson, Chair

Department of Physical Oceanography 


\begin{abstract}
The Arabian Sea is strongly forced by monsoon winds. Surface moorings deployed in the Arabian Sea are exposed to high winds and large waves. The waves, generated by strong wind events, impose a dynamic load on all mooring components. The dynamic cycling of mooring components can be so severe that ultimate strength considerations are superseded by the fatigue properties of the standard hardware components.
\end{abstract}

Concerns about all in-line mooring components and their fatigue endurance dictated the need for an independent series of cyclic fatigue tests. The components tested included shackles of various sizes and configurations, wire rope, instrument cages, chain, and a variety of interconnecting links such as weldless sling links and end links. The information gained from these tests was used in the design of the surface moorings deployed in the Arabian Sea by the Upper Ocean Processes group of the Woods Hole Oceanographic Institution.

The results of the cyclic fatigue tests conducted in support of the Arabian Sea surface mooring design effort are presented in this report. Recommendations are made with regard to all in-line components for surface moorings where dynamic conditions might be encountered for extended periods. The fatigue test results from shackles, and sling links were compiled to generate an $\mathrm{S} / \mathrm{N}$ diagram where the cyclic stress amplitude is plotted versus the number of cycles to failure. In addition the wire rope test results were compiled with historical wire rope data from US Steel to generate a S/N diagram for torque balanced 3 x 19 wire rope. These results can be used in conjunction with future design efforts. 


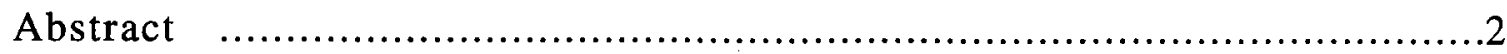

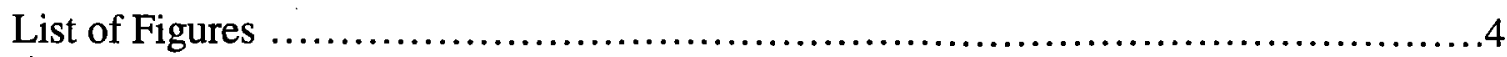

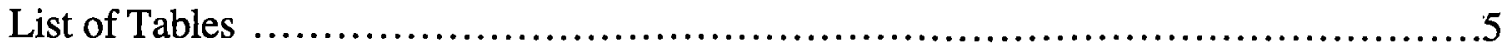

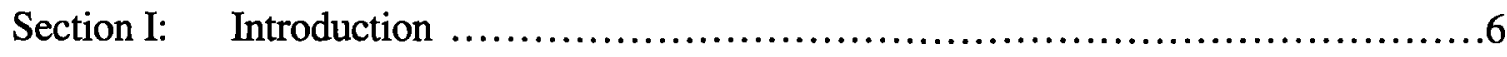

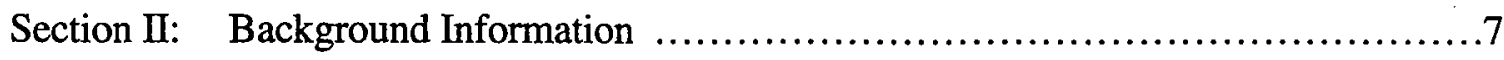

Section III: Arabian Sea Fatigue Tests ........................................... 11

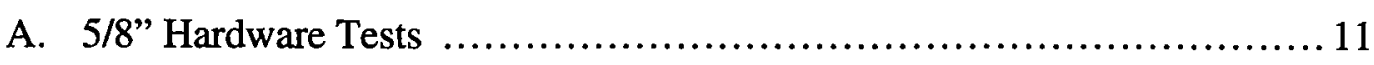

B. 3/4" Hardware Tests ............................................... 15

C. Cage Tests (First Series) ….................................................15

D. Cage Tests (Second Series) .......................................... 15

E. Wire Rope Tests (First Series) ..................................... 15

F. Wire Rope Tests (Second Series) ………...................................... 16

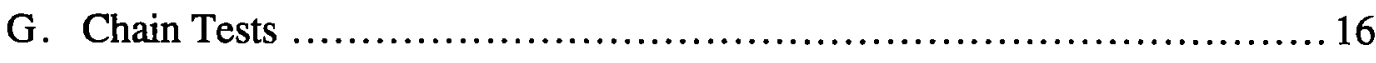

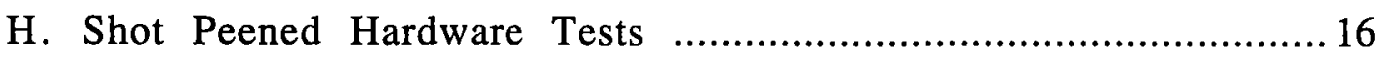

I. Load Range Selection .............................................. 17

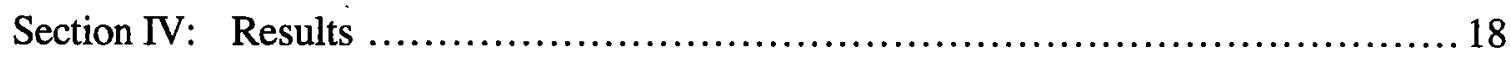

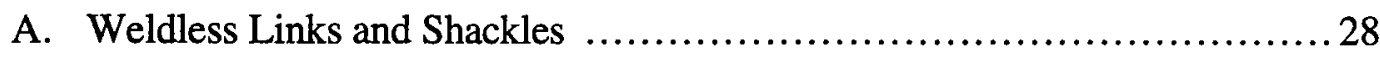

B. Shot Peened Shackles .............................................. 32

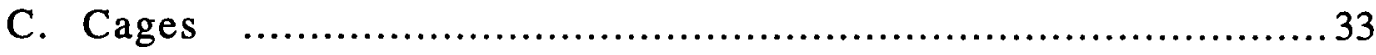

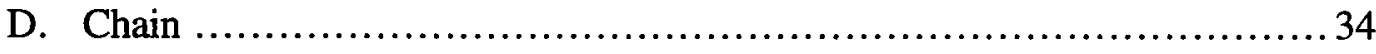

E. Wire Rope........................................................... 34

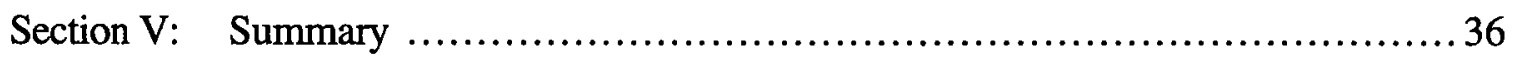

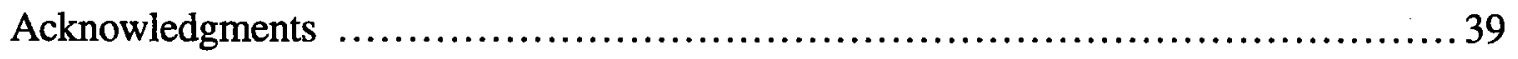

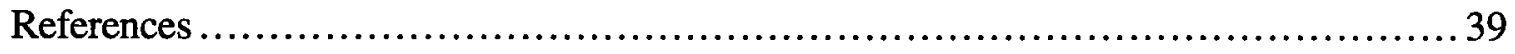

Appendix 1: Fatigue Test Data ............................................... 40 
Figure 1: Photograph and manufacturer specifications of the 5/8" Weldless Sling Link that failed during the 1989 deployment of the Marine Light in the Mixed Layer experiment pilot mooring.......................................

Figure 2: Photograph of the cyclic fatigue test setup while testing four strings of shackles.

Figure 3: Schematic of the "wiffle tree" configuration used during the fatigue testing of multiple strings of hardware components. Shown here are four strings of shackles with WHOI fabricated steel plate interconnecting links

Figures $4 \mathrm{a}$ to $4 \mathrm{u}$ show for specific component types, sizes and loading, the percentage of intact components as a function of the number of load cycles obtained during testing.

Figure 4a: 5/8" weldless sling links cycled between 400 and 6300 pounds. 19

Figure 4b: 5/8" weldless sling links cycled between 400 and 7200 pounds. 19

Figure 4c: 3/4" weldless sling links cycled between 400 and 7500 pounds. 20

Figure 4d: 3/4" weldless sling links cycled between 400 and 8800 pounds. 20

Figure 4e: 3/4" weldless sling links cycled between 400 and 10,200 pounds. 20

Figure 4f: 5/8" anchor shackles cycled between 400 and 6300 pounds. 21

Figure 4g: 5/8" anchor shackles cycled between 400 and 7200 pounds. 21

Figure 4h: 3/4" anchor shackles cycled between 400 and 6800 pounds. .............. 22

Figure 4i: 3/4" anchor shackles cycled between 400 and 7500 pounds. .................... 22

Figure 4j: 3/4" anchor shackles cycled between 400 and 8800 pounds. .................... 22

Figure 4k: 3/4" chain shackles cycled between 400 and 6800 pounds. ...................... 23

Figure 41: 3/4" chain shackles cycled between 400 and 10,200 pounds. .............23

Figure 4m: 5/8" shot peened anchor shackles cycled between 2000 and 6000 pounds. .. 24

Figure $4 \mathrm{n}: 3 / 4$ " chain shackles cycled between 2000 and 6000 pounds. ................24

Figure 4o: 3/4" shot peened anchor shackles cycled between 2000 and 6000 pounds. ... 24

Figure 4p: 3/4" chain cycled between 2000 and 6000 pounds. .......................25

Figure 4q: 7/8" weldless end links cycled between 2000 and 6000 pounds. ...........25 
Figure 4r: 7/16" torque balanced wire rope cycled between 400 and 6800 pounds. ..... 26

Figure 4s: 7/16" torque balanced wire rope cycled between 2000 and 6000 pounds. ... 26

Figure 4t: VMCM-like cages with shortened 3/4" cage rods cycled between

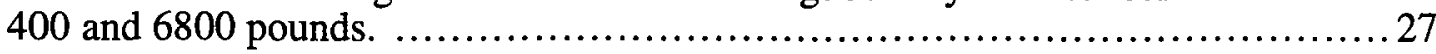

Figure 4u: VMCM-like cages with shortened 3/4" cage rods cycled between 2000 and 6000 pounds.

Figure 5: Three-dimensional representation of the number of cycles to first failure as a function of load range for two types of shackles and two sizes of weldless sling links.

Figure 6: $\mathrm{S} / \mathrm{N}$ diagram for shackles and sling links.

Figure 7: S/N diagram for $3 \times 19$ torque balanced wire rope. Load amplitude is an effective amplitude based on a mean tension of 4000 pounds.

Figure 8. S/N diagram for $3 \times 19$ torque balanced wire rope. Load amplitude is the actual amplitude used during the cyclic testing. 37

List of Tables

Table 1: Crosby cyclic fatigue test results. 10

Table 2: Summary of WHOI cyclic fatigue test data. 14 


\section{Section I: Introduction}

Materials tests conducted on a variety of mooring hardware components produced interesting results which were needed to specify the type of hardware to be used on the WHOI surface mooring deployed in the Arabian Sea in October 1994 and April 1995. Special care was taken during the design of the Arabian Sea surface mooring since environmental conditions there are believed to be more severe than in other regions where surface moorings have been deployed in the past.

For years the efforts to investigate air-sea interaction and upper ocean variability with surface moorings have focused on regions characterized by light to moderate atmospheric forcing. Wind and wave conditions have therefore not been considered critical factors in the design process. The desire to increase the understanding of air-sea interaction processes has required the capability to make time series observations of both forcing and response in severe environments. Surface moorings must now be designed for severe environments with strong atmospheric forcing along with the steady current conditions. Waves generated by strong wind events impose a dynamic load on mooring components. Superimposed on the background static tension from the currents is an oscillating dynamic tension generated by each passing wave. The dynamic cycling can be so severe that ultimate strength considerations are superseded by the fatigue properties of the standard hardware components.

Since the environmental conditions in the Arabian Sea are generally thought to be more severe than in other regions where surface moorings have been deployed an intense mooring design effort was launched. The Arabian Sea surface mooring design study included: (1) the collection of existing current, wave, and wind data; (2).use of that data in a static and dynamic mooring design study; and (3) laboratory materials testing. The materials tests were guided by the results of the mooring design study and provided input to the choice of hardware used in the surface mooring. Of particular interest here are the results of the laboratory materials testing that was done in support of the Arabian Sea design effort.

Concerns about all in-line mooring components and their fatigue endurance dictated the need for an independent series of cyclic fatigue tests. The components tested included shackles of various sizes, configurations, and manufacturers, wire rope, instrument cages, chain, and a variety of interconnecting links such as weldless sling links and end links. 


\section{Section II: Background Information}

A standard, off-the-shelf, oceanographic surface mooring design does not exist. The surface mooring, like the subsurface mooring, is a tool that must be tailored every time it is used to meet the requirements for which it is intended. The first order requirement is that it must remain on station for the duration of the intended deployment. From that basic goal one can begin to specify the desired performance criteria (i.e., inclination, tensions, watch circle) all of which are affected by the expected environmental conditions (i.e., wind, wave, and current conditions), water depth, the number of instrument packages to be deployed, instrument sizes and weights, their location in the water column and mooring component sizes, weights and lengths. The greatest unknown in the design effort is usually the expected environmental conditions.

Historically the ocean current in the region where a mooring was to be deployed was the primary forcing factor considered in the design process. Mooring performance under the influence of a steady state current has been modeled. If the model is exercised by several current profiles the performance of the mooring can be evaluated under a range of conditions. Typically three current profiles are used to evaluate the static performance of the mooring. One profile depicts the normal conditions expected for the area. This is called the design current profile. The mooring is designed to meet all of the performance specifications when subjected to the design current profile. A second current profile used in the design process consists of the most severe currents either previously observed or anticipated for the site. This is called the survival current profile. The mooring must be able to survive (i.e., not break or part) when subjected to a survival current profile. The mooring performance criteria are temporarily overlooked under such conditions as long as the mooring does not break. The third profile. used in the design process is a low current condition. The purpose of examining mooring performance in low currents is to check the inclinations of individual components in low currents and to make sure that the chances for tangling or chafing are minimal.

The steady state currents impose a static load on all mooring components. Under static load the integrity of the mooring is based solely on the ultimate strength of the various mooring components. There are, however, other factors that must be taken into consideration when working in high wind and wave conditions.

Waves passing by the surface buoy can generate periodic increases in mooring tension. With a typical wave period of approximately seven seconds, millions of cycles can be 
accumulated during a six month deployment. With this many tension cycles the fatigue strength of the various in-line components becomes a serious design consideration.

Little was known about the fatigue properties of standard components used in-line on a mooring prior to the 1989 pilot mooring for the Office of Naval Research (ONR) funded Marine Light in the Mixed Layer (MLML) experiment (Plueddemann et al., 1995). The MLML pilot mooring was deployed in April 1989, approximately 300 miles south of Iceland in 2845 meters of water. Though the mooring was intended to remain on station for 5 months it failed after only 70 days. A 5/8 inch Crosby Laughlin weldless sling link with a rated working load of 4200 pounds and an ultimate breaking strength of six times the working load limit (WLL) was the component that failed (Figure 1). A high frequency tension data logger at the base of the MLML pilot mooring buoy bridle recorded tensions that ranged from less than 1000 to over 8500 pounds which was well under the ultimate breaking strength of the sling link. Tension records showed changes of up to 5000 pounds over less than four seconds.

To investigate this problem the manufacturer of the slings links, Crosby, agreed to perform a series of cyclic tests at their facility in Tulsa, Oklahoma, on the 5/8" sling links. Links were cycled between 2000 and 4000 pounds at 5 cycles per second. Inspections were made after 500,000,1,000,000, and 2,000,000 cycles; however there were no obvious changes. The loading was changed to cycle between 420 and 6300 pounds, i.e., from a low load equal to $10 \%$ of the WLL to a high load equal to 1.5 times the WLL. Failure occurred after 52,800 cycles.

Further tests were conducted on additional new 5/8" links as well as 3/4" links and 5/8" anchor and chain shackles, and 3/4" anchor shackles. The results of those tests are in Table 1. Conclusions drawn from the testing and analysis of the failed component and similar components are that the link that failed on the MLML pilot mooring did so in fatigue. The origin of the crack was on the outside of the link, opposite the loaded area. No evidence of entrapped inclusions could be found. As indicated by concurrent testing at Crosby the fatigue limit had probably been exceeded and failure was only a matter of time under the loading conditions encountered during the life of this mooring. It was felt that an increase in link size from 5/8" to 3/4" would preclude further failure of this kind. In addition increasing the size of the shackle from $5 / 8$ " to $3 / 4$ " would also be a benefit. Since the $5 / 8$ " chain shackles faired better than the anchor shackles during the Crosby tests, it was also felt that wherever possible the chain style shackle should be used. 


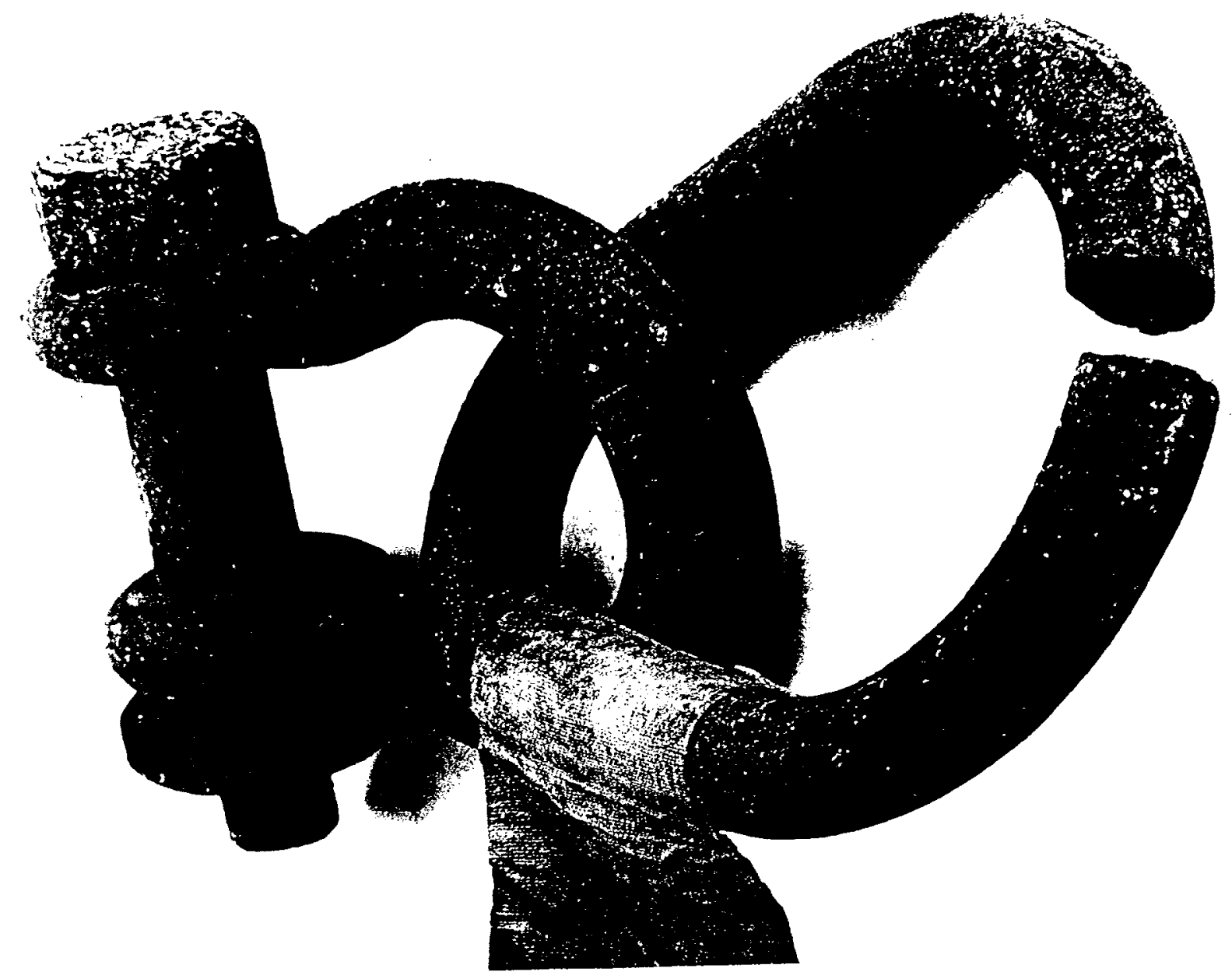

S-341 \& G-341

\section{WELDLESS SLING LINKS}

FORGED STEEL - QUENCHED \& TEMPERED

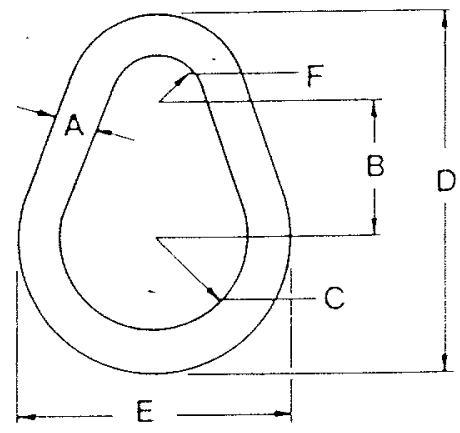

\begin{tabular}{|c|c|c|c|c|c|c|c|}
\hline $\begin{array}{c}\text { STOCK } \\
\text { DIA. } \\
\text { A }\end{array}$ & B & C & D & E & F & $\begin{array}{c}\text { WEIGHT } \\
\text { EACH }\end{array}$ & $\begin{array}{c}\text { WORK LOAD } \\
\text { SINGLE PULL } \\
\text { POUNDS }\end{array}$ \\
\hline $3 / 8$ & 1.13 & 75 & 3.00 & 2.25 & 38 & 23 & 1.800 \\
$1 / 2$ & 1.50 & 1.00 & 4.00 & 3.00 & 50 & .53 & 2.900 \\
$5 / 8$ & 1.875 & 1.25 & 5.00 & 3.75 & 63 & 11 & 4.200 \\
$3 / 4$ & 2.25 & 1.50 & 6.00 & 4.50 & 75 & 1.9 & 6.000 \\
$7 / 8$ & 2.63 & 175 & 700 & 5.25 & 88 & 2.9 & 8.300 \\
1 & 3.00 & 2.00 & 8.00 & 6.00 & 1.00 & 4.3 & 10.800 \\
$11 / 4$ & 4.00 & 2.50 & 10.25 & 7.50 & 125 & 85 & 16.750 \\
$13 / 8$ & 4.13 & 2.75 & 11.00 & 8.25 & 1.38 & 11.3 & 20.500 \\
\hline
\end{tabular}

- Minimum ultimate strength six tımes working load limil

Figure 1: Photograph and manufacturer specifications of the 5/8" weldless sling link that failed during the 1989 deployment of the Marine Light in the Mixed Layer experiment pilot mooring. 


\section{Table 1. Crosby cyclic fatigue test results.}

Component

$5 / 8$ " Weldless Sling Links

Cycled from 420 to 6300 pounds

3/4" Weldless Sling Links

Cycled from 420 to 6300 pounds

5/8" Anchor Shackles

Cycled from 420 to 6300 pounds

1

2

3

4

5

6

5/8" Chain Shackle

Cycled from 420 to 6300 pounds

3/4" Anchor Shackles

Cycled from 420 to 6300 pounds

1

2

5
507,000

151,910

122,170

464,000

116,000

207,000

$7 \quad 399,000$

$1 \quad$ No failure after $5,000,000$

2 No failure after $6,700,000$

$36,200,000$ (at 4-5 million cycles sample loaded to 30,000 pounds)

116,000

145,000

69,000

155,000

156,000

132,000

468,000

161,800

152,000

419,000

689,000
0,000 plus

$6 \quad 1,000,000$ plus 


\section{Section III: Arabian Sea Fatigue Tests}

If the sling links and shackles were susceptible to fatigue failure how would the other in-line components perform? To address these concerns an independent series of cyclic fatigue tests were conducted by Teledyne Brown Engineering, formerly of Woburn, MA, and more recently of Marion, MA, beginning in September 1993. The scope of the fatigue testing was expanded to include the majority of all in-line mooring components. The components tested included shackles of various sizes, configurations, and manufacturers, wire rope, instrument cages, chain, and a variety of links.

The machine used for the cyclic fatigue tests was a 100,000 pound capacity MTS servo hydraulic load frame. Figure 2 shows a typical setup while testing a series of shackles and weldless sling links. With the use of a "wiffle tree" (Figure 3) four strings of components could be tested at one time. The wiffle tree is used to compensate for any length differences between strings and therefore evenly distributes the load among the strings being tested. All tests were conducted in a dry environment. The frequency of the applied cyclic load was between 3 and $5 \mathrm{~Hz}$.

All tests consisted of a combination of components such as shackles and sling links connected in series. Each series of tests is described below. The name assigned to a particular test refers to the major component(s) under consideration even though several items were under test. A summary of the test results appears in Table 2. Appendix 1 contains the data collected from all the tests.

\section{A. 5/8" Hardware Tests}

The first series of tests were with new 5/8" Crosby anchor shackles and 5/8" Crosby weldless sling links. Four parallel strings made up of several shackle-weldless sling linkshackle (SLS) units were tested. The bow of the shackle was always dipped into the weldless sling link. Between any two SLS units there was a 3/4" steel plate with two holes to accept the shackle bolts of two adjacent SLS units. Two load ranges were specified. The first test cyclically loaded the components between 400 and 7200 pounds at a frequency of $3 \mathrm{~Hz}$. A second test with a new set of 5/8" hardware was cycled between 400 and 6300 pounds also at a frequency of $3 \mathrm{~Hz}$. 


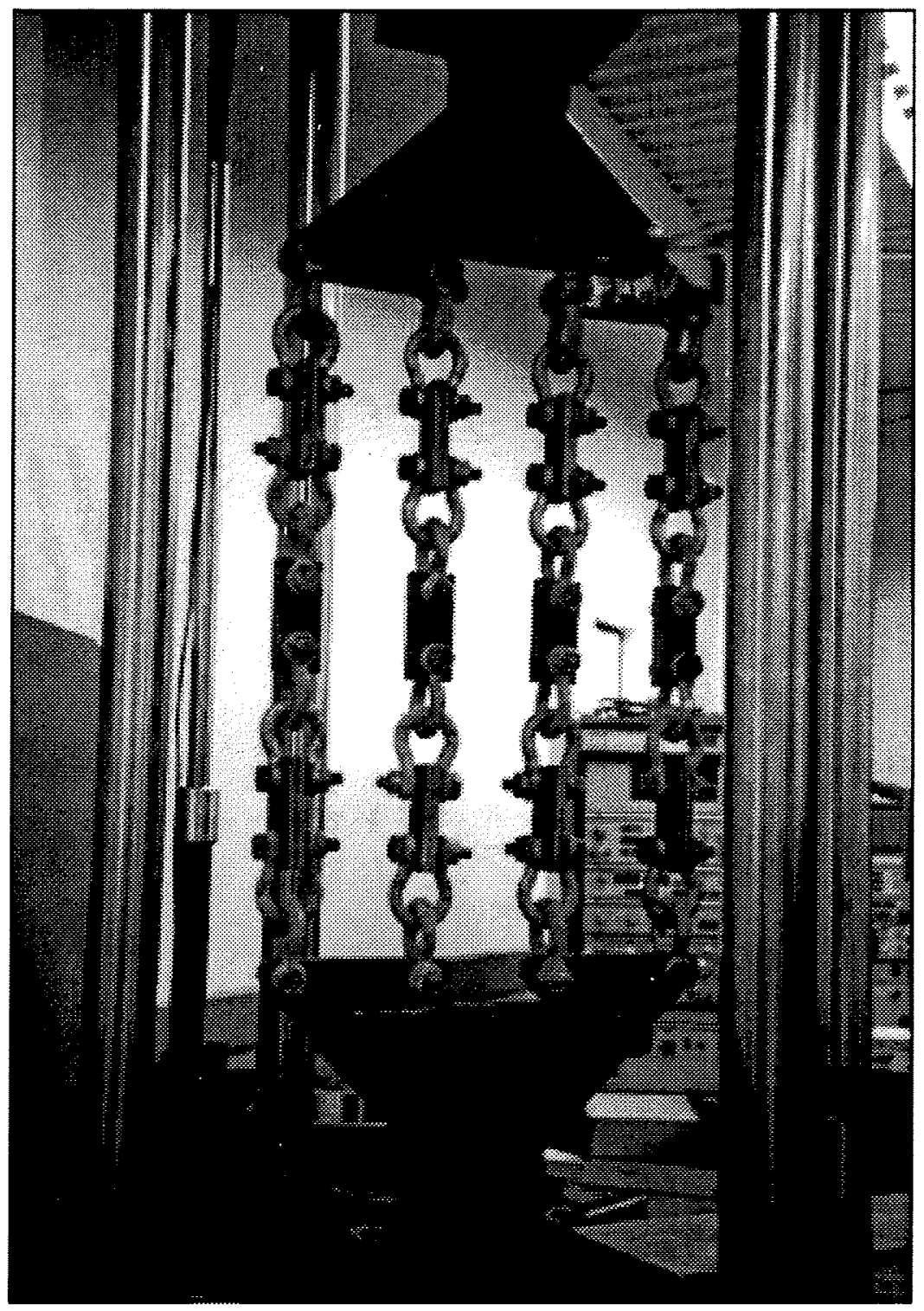

Figure 2: Photograph of the cyclic fatigue test setup while testing four strings of shackles. 


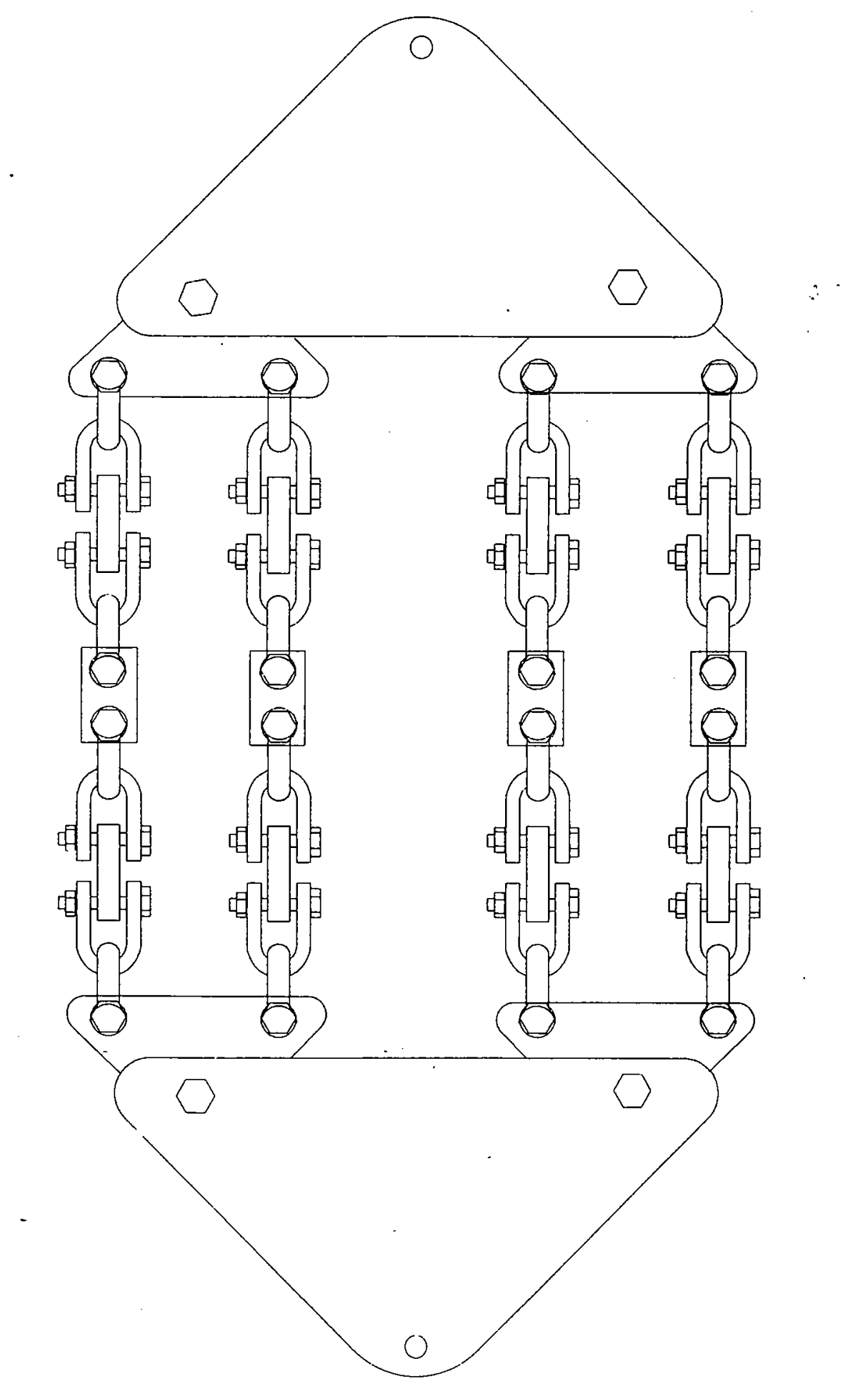

Figure 3: Schematic of the "wiffle tree" configuration used during the fatigue testing of multiple strings of hardware components. Shown here are four strings of shackles with WHOI fabricated steel plate interconnecting links. 


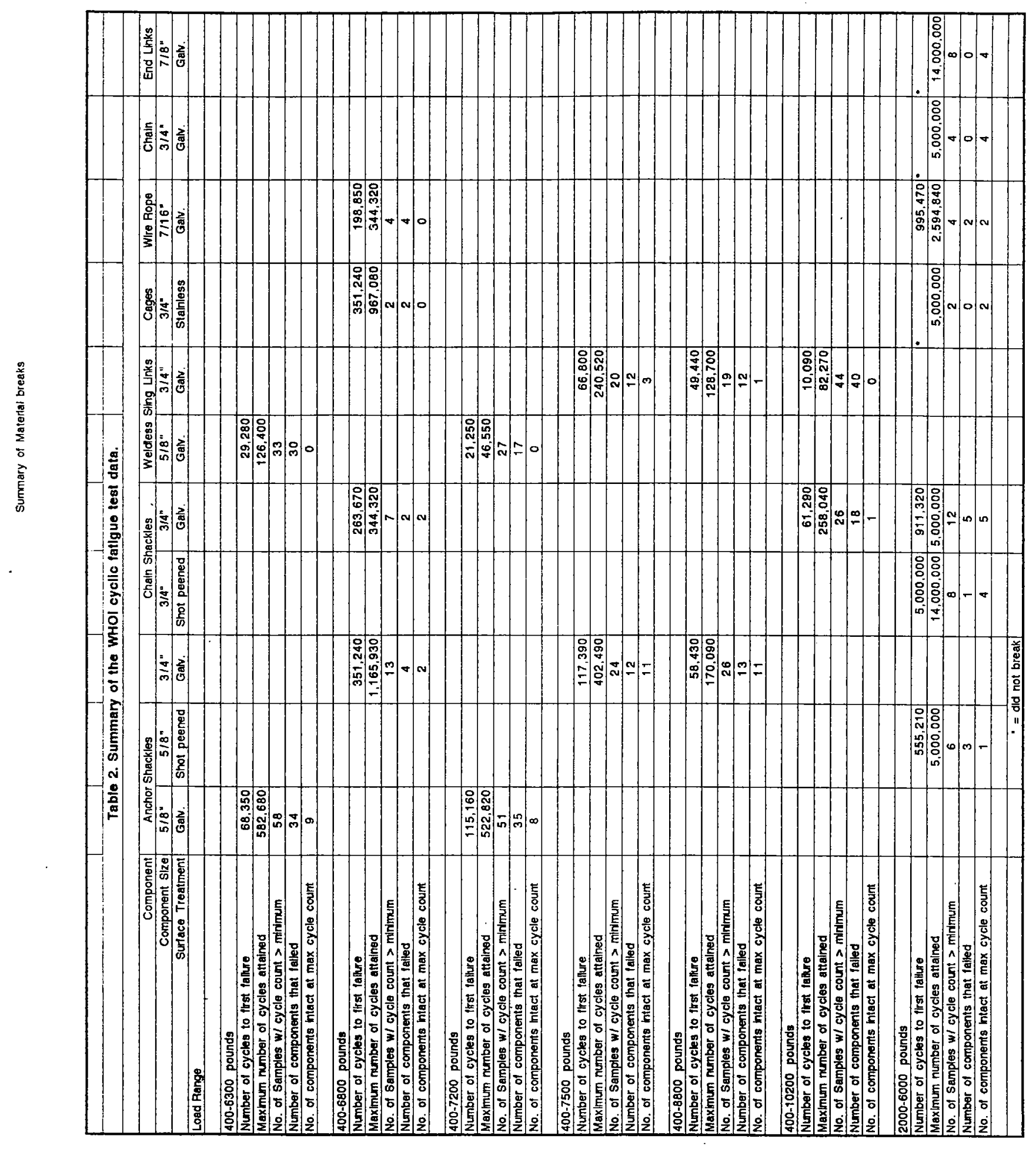




\section{B. 3/4" Hardware Tests}

The second series of tests were with new 3/4" Crosby chain shackles and weldless sling links. As with the earlier test each of the four parallel strings had several SLS units which were interconnected with the $3 / 4$ " steel plates. Three load ranges were selected for these tests. New hardware was used when the load ranges were changed. The first set of hardware were cycled between 400 and 10,200 pounds. A second test cycled a new set of hardware between 400 and 8800 pounds and a third load range used was between 400 and 7500 pounds.

\section{Cage Tests (First Series)}

The next fatigue test conducted had two short versions of the Vector Measuring Current Meter (VMCM) cage with 3/4" cage rods in line with 3/4" anchor shackles to hold the cages in the testing machine. The VMCM instrument cage goes in-line on a mooring just like a shackle or link and is therefore susceptible to fatigue failure. Since the test machine could not accommodate a full length cage (71 inches) a short version, 48 inches in length, was fabricated by Stonebridge Corp of Holliston, MA. Stonebridge was the same fabricator that had made all of the Upper Ocean Processes Group's previous VMCM cages. The cages were initially tested in parallel with two back to back shackles above and below each cage. The cages were cycled between 400 and 6800 pounds until failure. After the first cage failed the second cage was tested as a single string. Unbroken shackles from the first cage were used to replace hardware that broke during the testing of the second cage. Testing continued until both cages had failed.

\section{Cage Tests (Second Series)}

A second series of cage tests were conducted on two newly fabricated short versions of the VMCM instrument cage. Early cage failure during the previous cage tests were attributed to poorly defined fabrication specifications. Two cages fabricated to new specifications were donated by Stonebridge Corporation. The new test cages were slightly shorter (37" versus 48 ") than the pair tested earlier. Above and below each cage there was a shot peened 3/4" Crosby chain shackle, a 7/8" Crosby weldless end link, and a shot peened 5/8" Crosby anchor shackle. The-shot peened 3/4" chain shackle and the 7/8" weldless end link were previously tested to 5 million cycles during the chain test. The shot peened 5/8" shackles were new. All hardware was cycled between $2000-6000$ pounds. The test was terminated after five million cycles.

\section{E. Wire Rope Tests (First Series)}

Four 7/16" diameter, polyethylene jacketed, torque balanced, $3 \times 19$ wire rope samples each 42 " long with swaged fittings at both ends were tested. The MacWhyte wire rope 
samples were swaged using National closed swage fittings by the WHOI rigging shop. The four samples were tested in parallel until the first failure occurred. Two samples were then tested in parallel until only one sample was left which was then tested as a single string. Two back to back 3/4" shackles were placed above and below each wire rope sample. Five of the shackles used with the wire rope were anchor shackles from the cage tests previously conducted. The remainder were new chain shackles. The wire rope was cycled between 400 and 6800 pounds. Testing was terminated when all four wire samples were broken.

\section{F. Wire Rope Tests (Second Series)}

Early failure of the first wire samples prompted a second series of tests on four new shots of 7/16" diameter wire rope that was also swaged by the WHOI rigging shop. It was suspected that proper swaging techniques had not been followed for the first samples. The test setup was similar to the first series of wire tests except that new Crosby 3/4" chain type shackles were used back to back above and below the wire samples. The wire rope was cycled between 2000 and 6000 pounds. After the second wire failure the test was terminated.

\section{G. Chain tests}

Four strings of Campbell 3/4" system 3 proof coil chain were tested in parallel. The chain samples were each 36" in length and had a shot peened 3/4" Crosby chain shackle, a 7/8" Crosby weldless end link and a 3/4" Crosby chain shackle above and below it. All hardware was cycled between 2000 and 6000 pounds. The test was terminated after reaching five million cycles.

\section{H. Shot Peened Hardware}

Bigger is not always better. Increasing the size of mooring hardware drives up the cost and further restricts the carrying capacity of the mooring. It can also require instrument redesign if the load carrying member cannot accommodate the larger hardware. In an effort to improve the fatigue life of various hardware components without increasing their size, several test samples were shot peened prior to fatigue testing. Shot peening is a process whereby a component is blasted with small spherical media called shot in a manner similar to the process of sand blasting. It differs from sand blasting in that the media used in shot peening is more rounded rather than angular and sharp as in sand blasting. Each piece of shot acts like a small ball peen hammer and tends to dimple the surface that it strikes. At each dimple site the surface fiber of the material is placed in tension. Immediately below the surface of each dimple the material is highly stressed in compression so as to counteract the tensile stress at the surface. A shot peened part with its many overlapping dimples therefore has a surface layer with residual 
compressive stress. Cracks do not tend to initiate or propagate in a compressive stress zone. Since cracks usually start at the surface, a shot peened component will take longer to develop a crack thereby increasing the fatigue life of the part. Many materials will also increase in surface hardness due to the cold working effect of shot peening.

The compressive stresses introduced by shot peening increase the resistance to fatigue failures, corrosion fatigue, stress corrosion cracking, hydrogen assisted cracking, fretting, galling, and erosion caused by cavitation. The benefits of cold working include work hardening, and intergranular corrosion resistance.

Samples of 3/4" Crosby chain shackles and 5/8" anchor shackles were shot peened by Metal Improvement Company, Inc. of Windsor, Connecticut, at their Lynn, Massachusetts, plant. The shot size used was MI-330, the intensity was .012 to $.016 \mathrm{~A}$ with $100 \%$ coverage per Mil Spec 13165C, Section 6.11, method b.

\section{Load Range Selection}

During the fatigue tests the components are repeatedly cycled from a minimum tensile load to a maximum load at about $3 \mathrm{~Hz}$. The loads selected for these cyclic tests were initially based on those specified for the first series of tests conducted by Crosby following the MLML 89 pilot mooring failure. The component in question at that time was a 5/8" weldless sling link which has a working load limit of 4200 pounds. The minimum load was $10 \%$ of the working load limit and the maximum load was 1.5 times the working load limit or 400 to 6300 pounds. Since the original Crosby tests had used that range we wanted to duplicate those tests to see how repeatable the results were. The first tests conducted were therefore on $5 / 8$ " hardware using the 400 to 6300 pound range.

It was our desire to develop an $\mathrm{S} / \mathrm{N}$ curve for the various hardware components. The $\mathrm{S} / \mathrm{N}$ curve shows the relationship between stress amplitude (S) and the number of cycles to failure (N). Several tests were conducted at different load ranges to see what affect it would have on the number of cycles to failure. (Load range is defined here as the maximum tension minus the minimum tension attained for each loading cycle. For example, a sample cycled between 2000 and 6000 pounds has a load range of 4000 pounds.) We hypothesized that

cyclic loads between 400 and 7200 pounds would decrease the number of cycles to failure by an order of magnitude. In addition, a cyclic test between 400 and 5300 pounds was planned in order to obtain an order of magnitude increase in the number of cycles to failure. Although 
the 400 to 5300 pound cyclic test was never actually conducted the range was utilized in planning the loads for larger hardware sizes.

The 5/8" hardware fatigue results from the 400 to 6300 and 400 to 7200 tests indicated that the 5/8" hardware would not be appropriate for those sections of the mooring where large dynamic tensions could be found. Rather than continue testing the $5 / 8$ " hardware, tests were started on the $3 / 4$ " size hardware. The loads chosen for the $3 / 4$ " hardware were the result of increasing the maximum tension used for the $5 / 8$ " hardware by a factor of 1.4 which is. proportional to the cross sectional areas of the two hardware sizes.

The first series of cage and wire rope tests were conducted using cyclic loads from 400 to 6800 pounds. This range was chosen because it encompassed $99 \%$ of the tensions seen by the MLML mooring (M. Grosenbaugh, personal communication). Following the first series of cage and wire rope tests the tensions were changed to cycle between 2000 to 6000 pounds. The tests cycling between 400 and 6800 pounds were thought to be an extreme condition and it was unlikely that every tension cycle experienced by the mooring would be over that full range. The more realistic 2000 to 6000 pound tests represent a static load of 4000 pounds tension from the weight of the mooring components and the drag from a steady state design current coupled with a $+/-2000$ pound dynamic tension from the surface wave conditions.

\section{Section IV: Results}

The following figures (Figures $4 \mathrm{a}$ to $4 \mathrm{u}$ ) show for a particular size, type and load range the percentage of samples intact with increasing number of cycles. All like components (size and type) tested with the same load ranges are grouped together. For example the 3/4" anchor shackles tested between 400 and 6800 pounds are separate from the 3/4" chain shackles tested over the same range. The data used to generate these figures include all component failures plus those components that attained the maximum number of cycles and remained intact. Some variation in scales was necessary to adequately show the details. All weldless sling links are plotted to the same scale. The scales used in plotting the data for all the 5/8" and 3/4" hardware with the exception of the sling links mentioned above and tests cycled between 2000 and 6000 pounds are the same. Test results from the cages, wire rope, chain, weldless endlinks, and $5 / 8$ " and 3/4" hardware tested between 2000 and 6000 pounds have also been plotted with the same scale for comparison purposes. The weldless sling link data were grouped in bins of 5000 cycles while all other data were grouped in bins of 10000 cycles. 


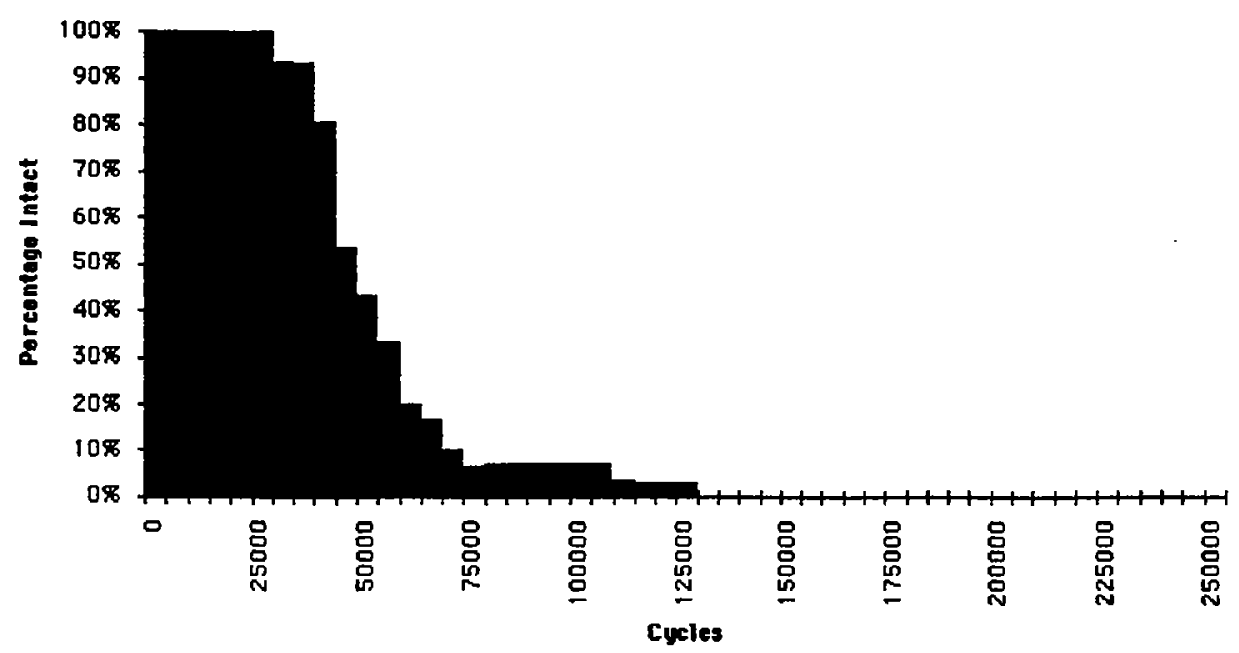

Figure 4a. 5/8" Weldless Sling Links cycled between 400 and 6300 pounds. The blackened section depicts the percentage of samples intact at the cycles indicated. The sample size was $\mathbf{3 0}$ and the test was terminated at 126,400 cycles with no intact samples remaining.

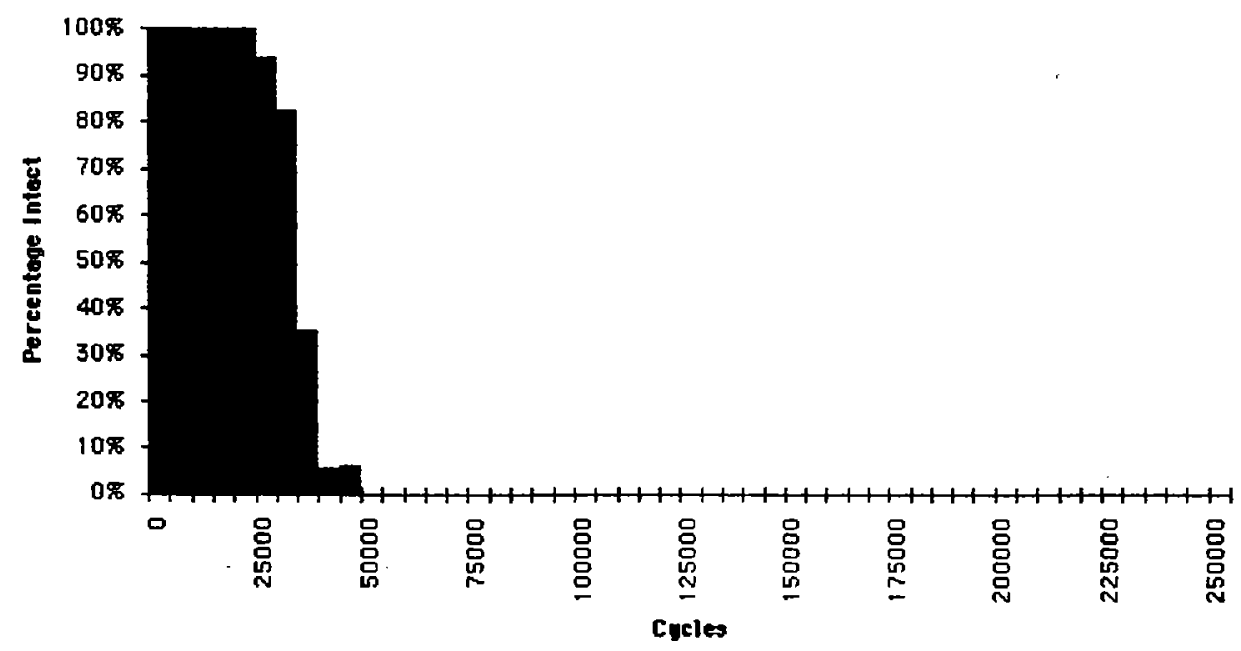

Figure 4b. 5/8" Weldless Sling Links cycled between 400 and 7200 pounds. The blackened section depicts the percentage of samples intact at the cycles indicated. The sample size was 17 and the test was terminated at 46,550 cycles with no intact samples remaining. 


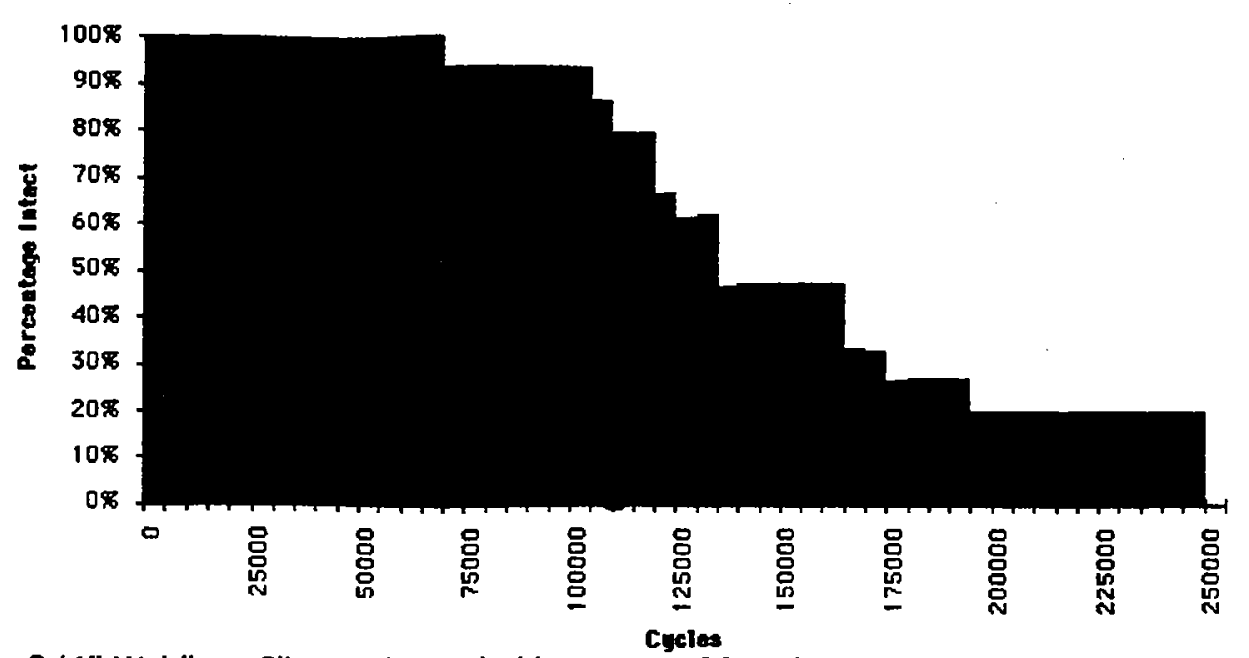

Figure 4c. 3/4" Weldless Sling Links cycled between 400 and 7500 pounds. The blackened section depicts the percentage of samples intact at the cycles indicated. The sample size was 15 and the test was terminated at 240,520 cycles with three intact samples remaining.

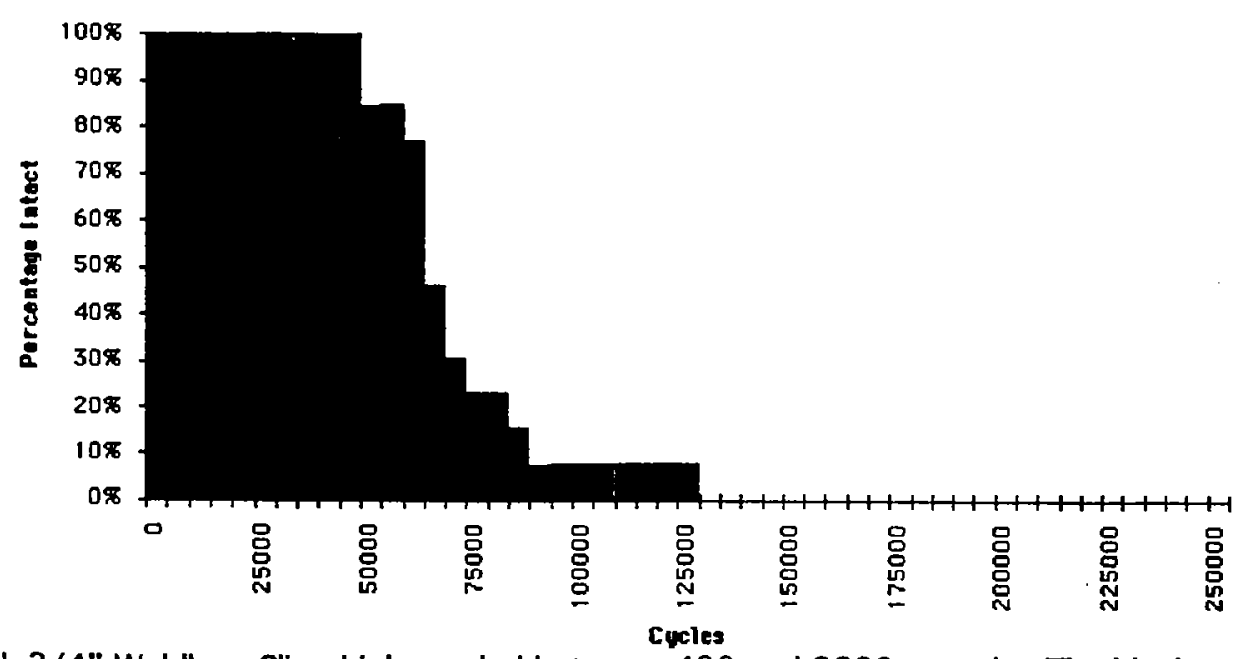

Figure 4d. 3/4" Weldless Sling Links cycled between 400 and 8800 pounds. The blackened section depicts the percentage of samples intact at the cycles indicated. The sample size was 13 and the test was terminated at 128,700 cycles with one intact sample remaining.

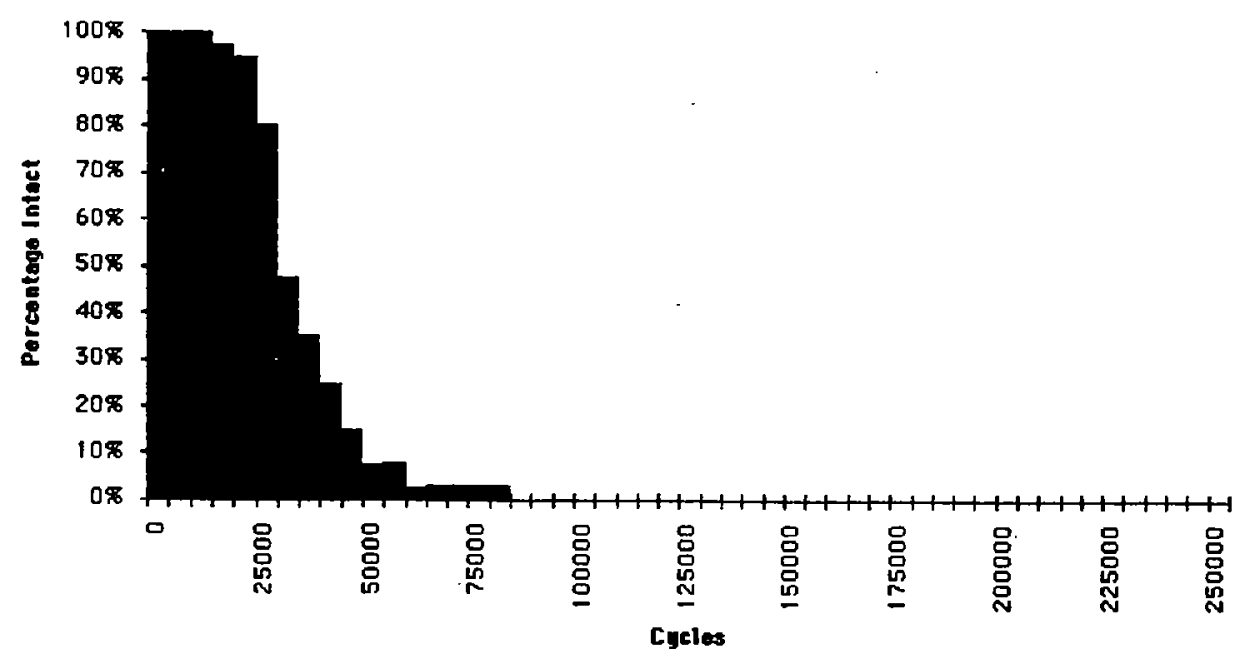

Figure 4e. 3/4" Weldless Sling Links cycled between 400 and 10,200 pounds. The blackened section depicts the percentage of samples intact at the cycles indicated. The sample size was $\mathbf{4 0}$ and the test was terminated at 82,270 cycles with no intact samples remaining. 


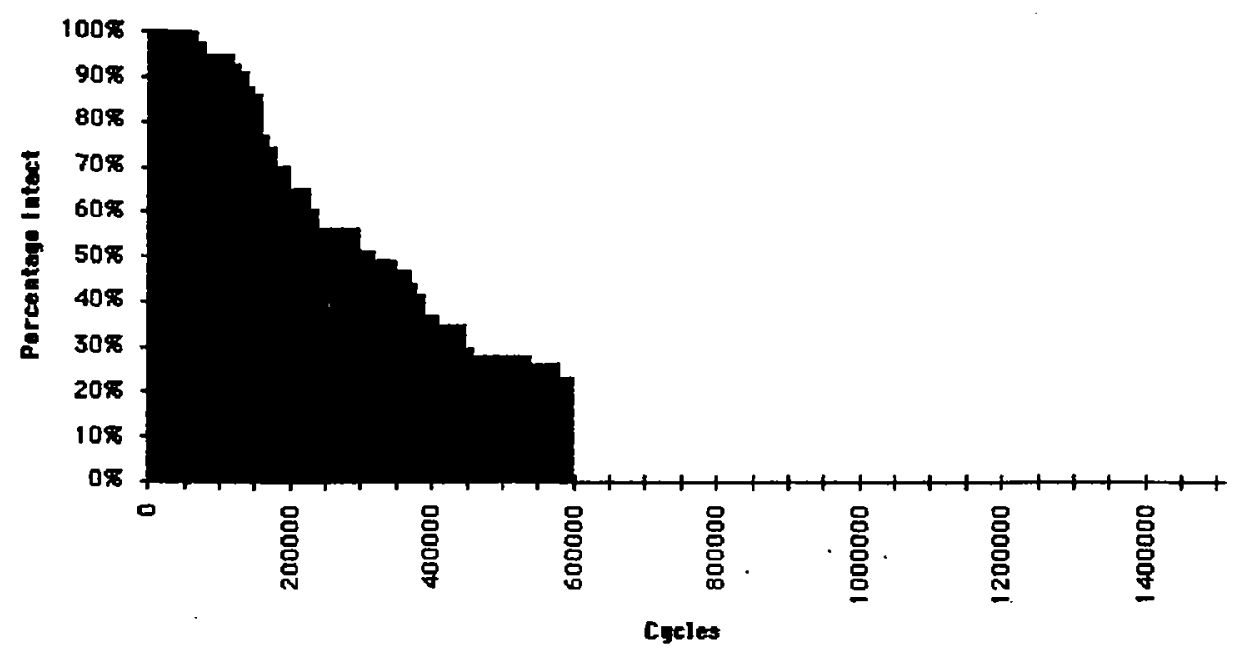

Figure 4f. 5/8" Anchor Shackles cycled between 400 and 6300 pounds. The blackened section depicts the percentage of samples intact at the cycles indicated. The sample size was $\mathbf{4 3}$ and the test was terminated at 582,680 cycles with ten intact samples remaining.

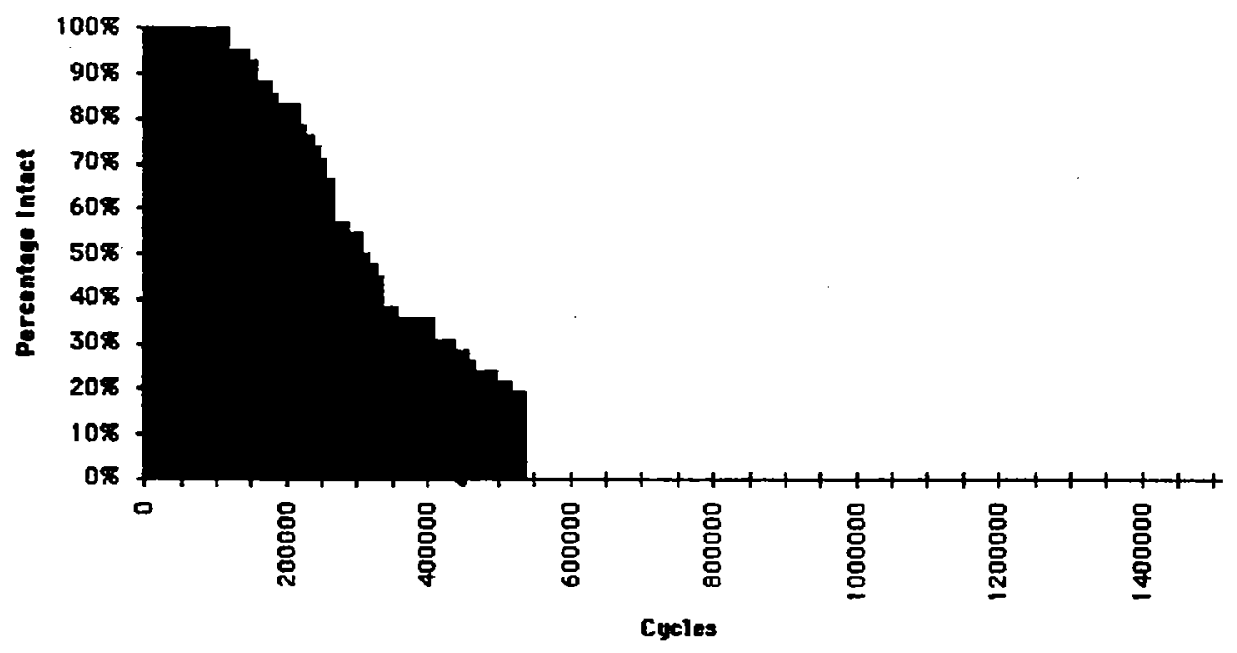

Figure 4g. 5/8" Anchor Shackles cycled between 400 and 7200 pounds. The blackened section depicts the percentage of samples intact at the cycles indicated. The sample size was 42 and the test was terminated at 522,820 cycles with eight intact samples remaining. 


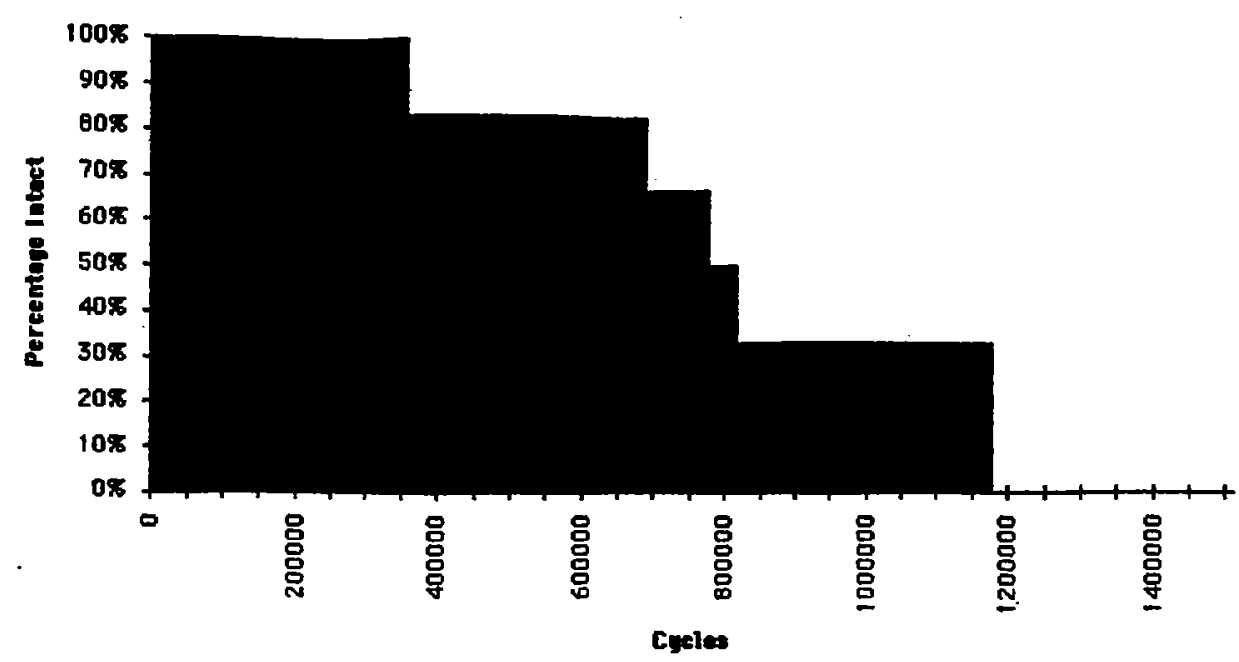

Figure 4h. 3/4" Anchor Shackles cycled between 400 and 6800 pounds. The blackened section depicts the percentage of samples intact at the cycles indicated. The sample size was 6 and the test was terminated at $1,165,930$ cycles with two intact samples remaining.

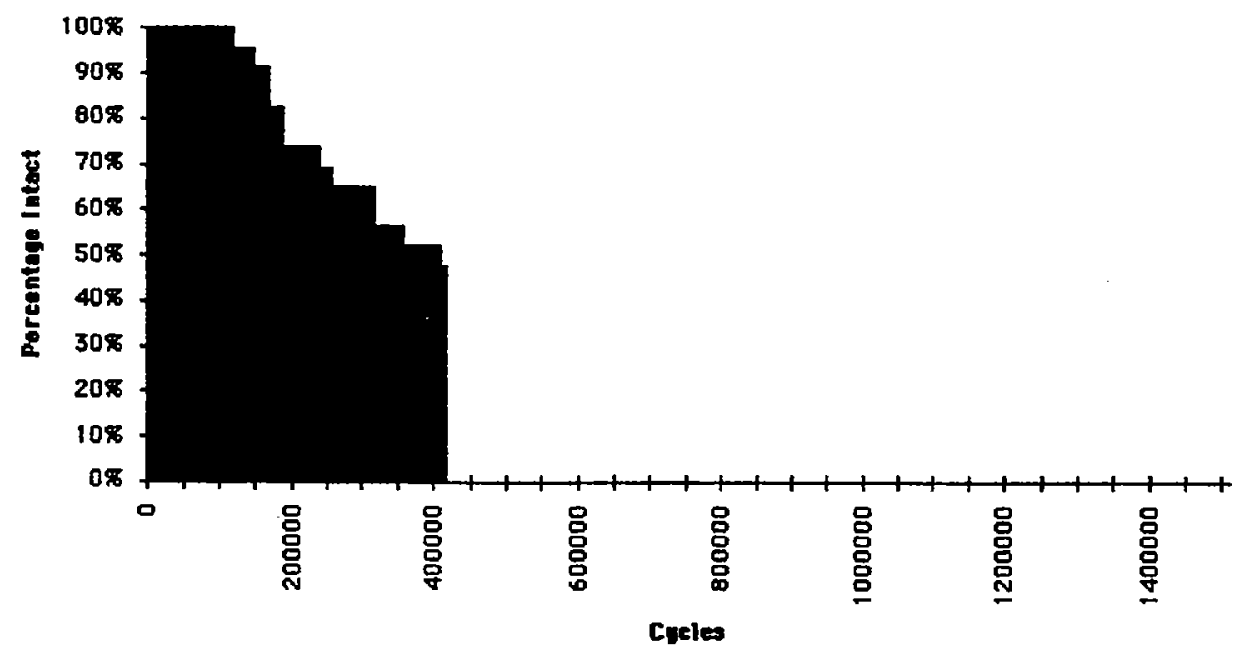

Figure 4i. 3/4" Anchor shackles cycled between 400 and 7500 pounds. The blackened section depicts the percentage of samples intact at the cycles indicated. The sample size was 23 and the test was terminated at 402,490 cycles with eleven intact samples remaining.

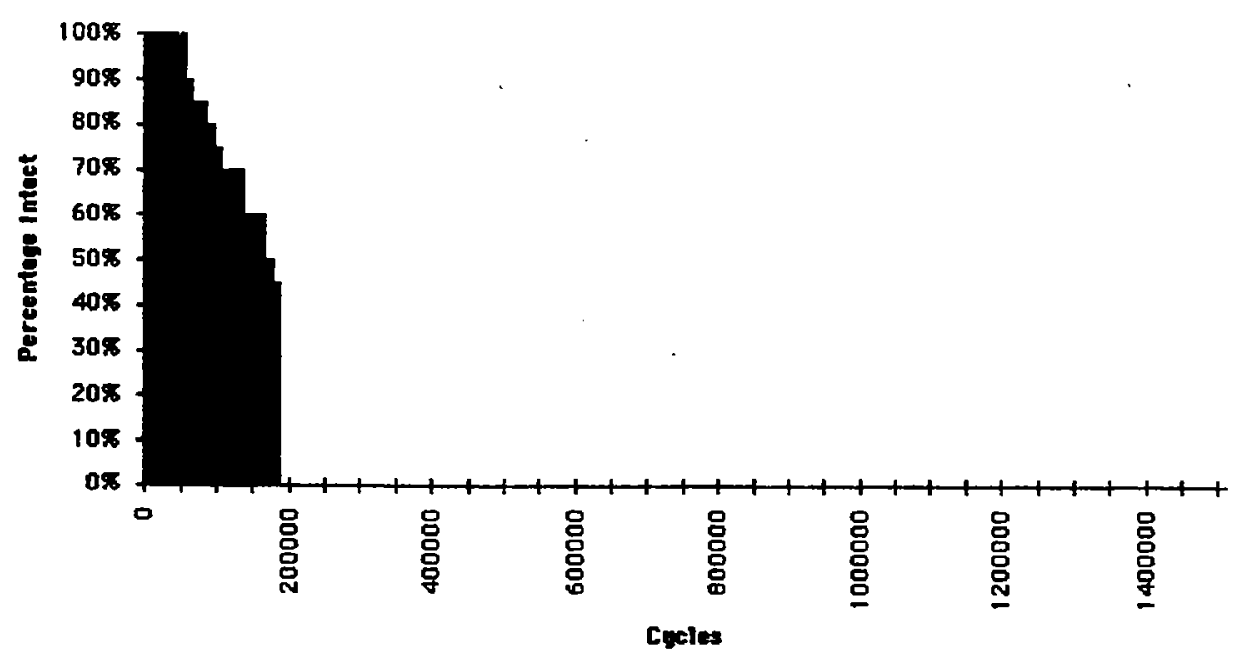

Figure 4j. 3/4" Anchor Shackles cycled between 400 and 8800 pounds. The blackened section depicts the percentage of samples intact at the cycles indicated. The sample size was $\mathbf{2 0}$ and the test was terminated at 170,090 cycles with eight intact samples remaining. 


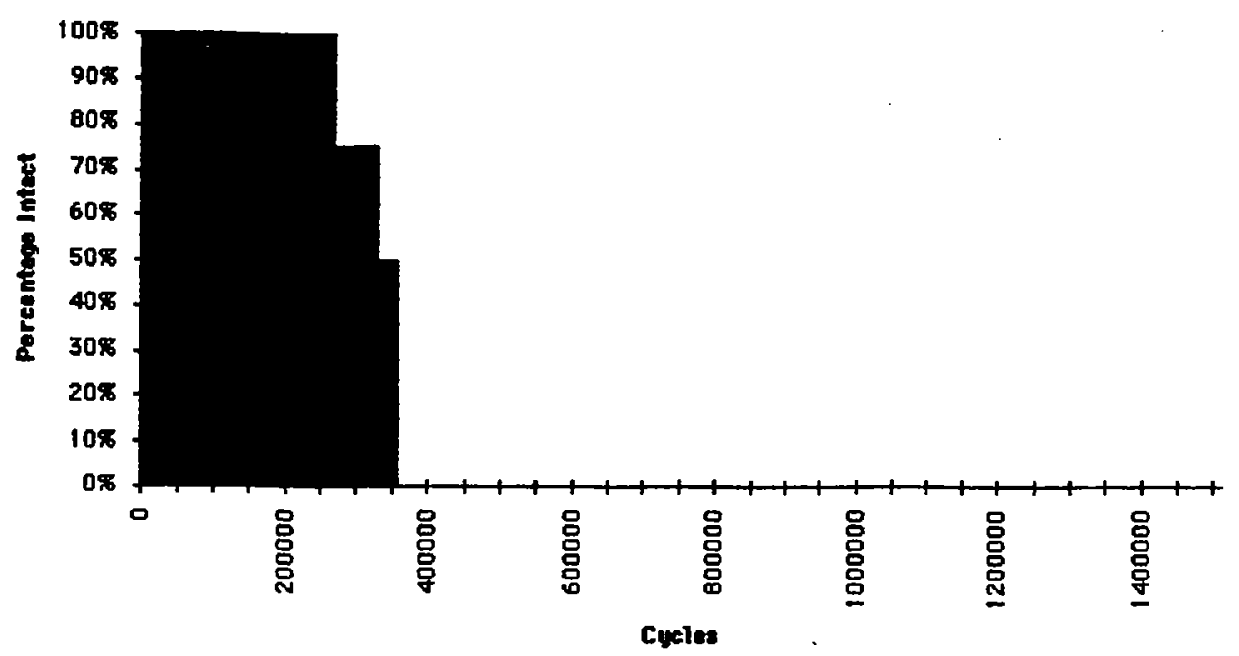

Figure 4k. 3/4" Chain Shackles cycled between 400 and 6800 pounds. The blackened section depicts the percentage of samples intact at the cycles indicated. The sample size was 4 and the test was terminated at 344,320 cycles with two intact samples remaining.

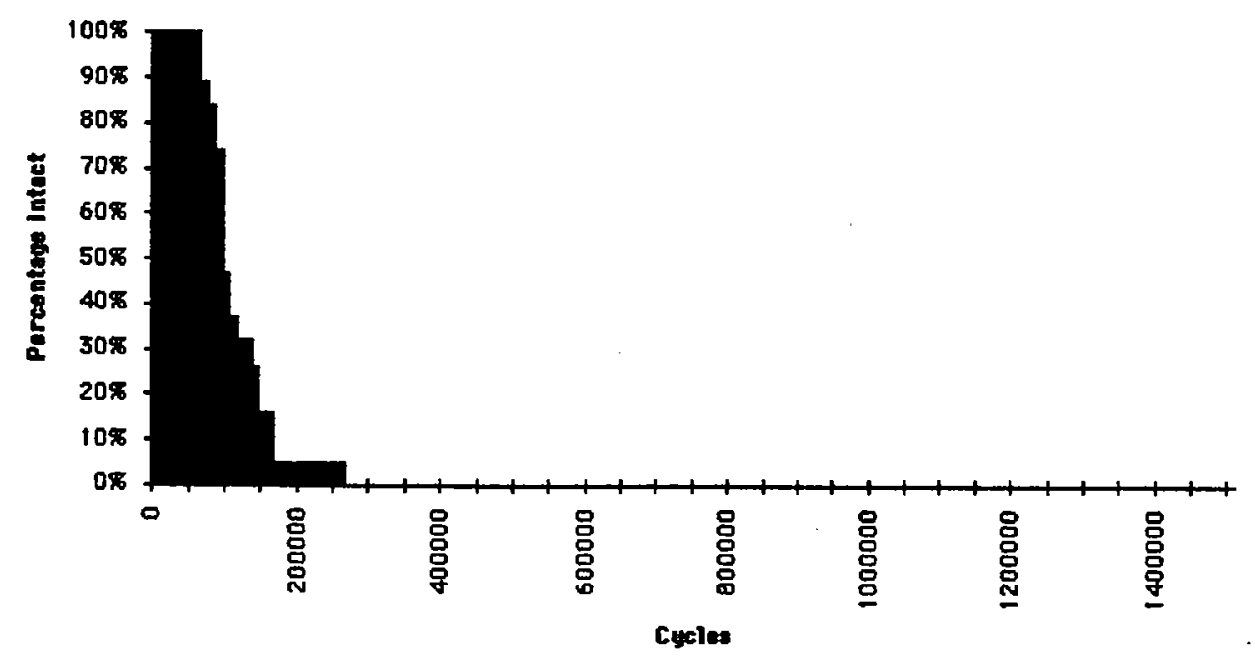

Figure 41. 3/4" Chain Shackles cycled between 400 and 10,200 pounds. The blackened section depicts the percentage of samples intact at the cycles indicated. The sample size was 19 and the test was terminated at 258,040 cycles with one intact sample remaining. 


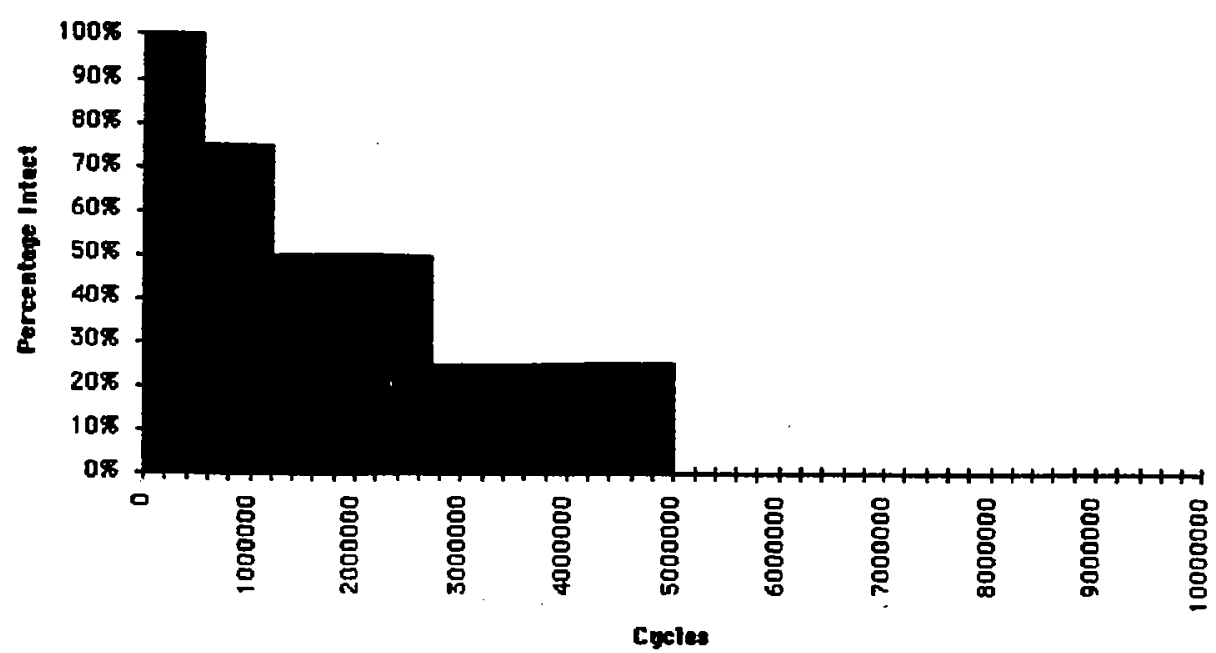

Figure 4m. 5/8" Shot Peened Anchor Shackles cycled between 2000 and 6000 pounds. The blackened section depicts the percentage of samples intact at the cycles indicated. The sample size was 4 and the test was terminated at $5,000,000$ cycles with one intact sample remaining.

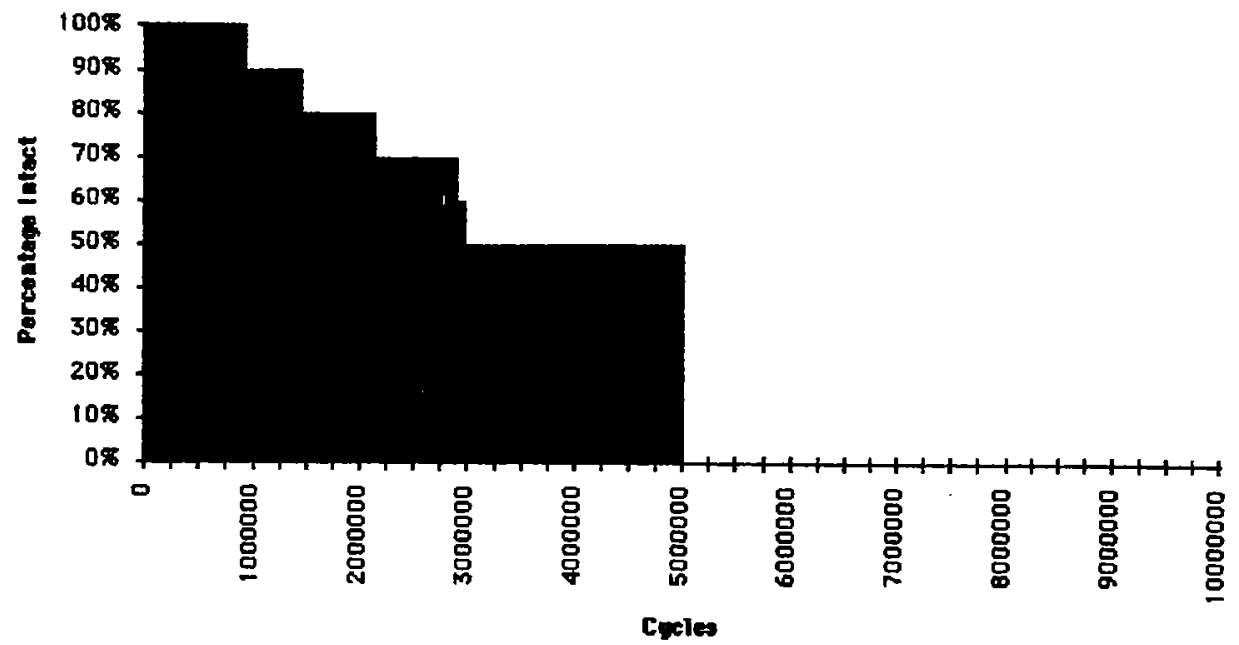

Figure 4n. 3/4" Chain Shackles cycled between 2000 and 6000 pounds. The blackened section depicts the percentage of samples intact at the cyctes indicated. The sample size was 10 and the test was terminated at $5,000,000$ cycles with five intact samples remaining.

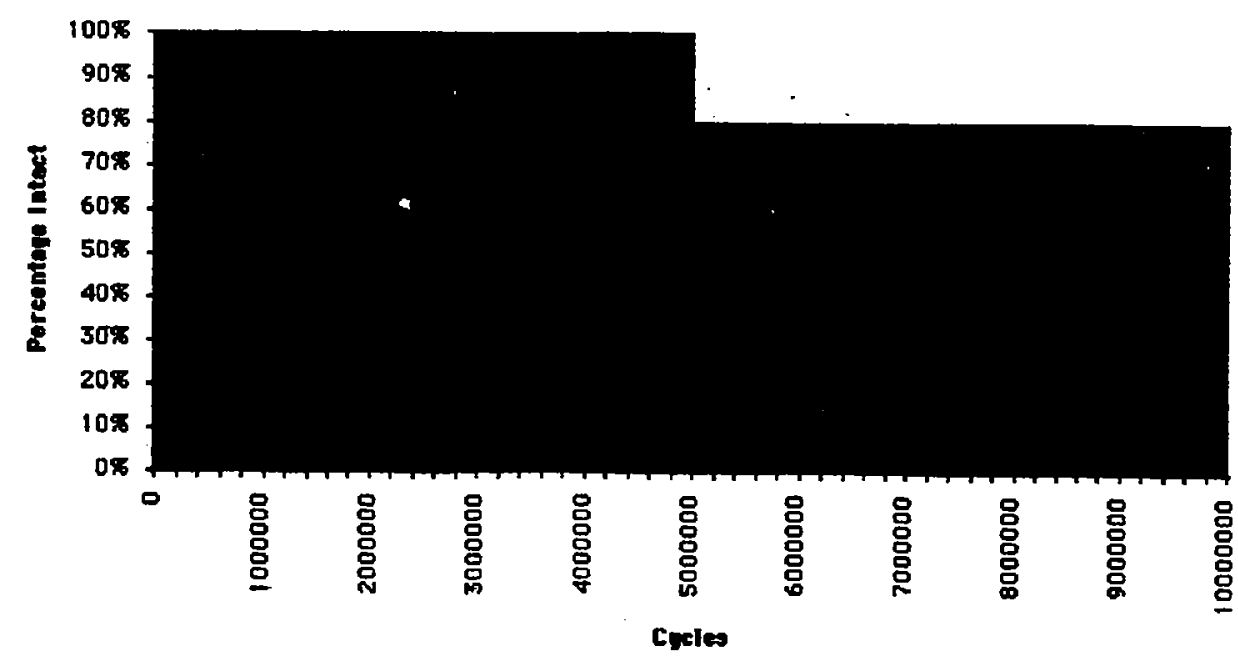

Figure 40. 3/4" Shot Peened Chain Shackles cycled between 2000 and 6000 pounds. The blackened section depicts the percentage of samples intact at the cycles indicated. The sample size was 5 and the test was terminated at 10,000,000 cycles with four intact samples remaining. 


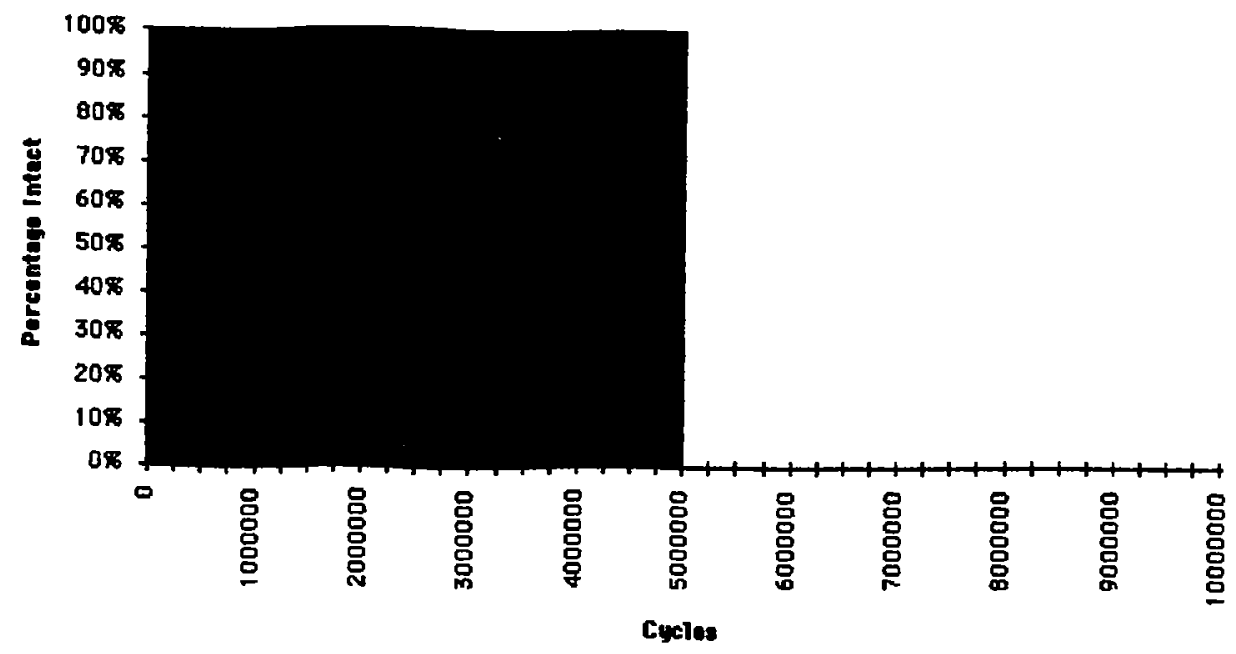

Figure 4p. 3/4" Chain cycled between 2000 and 6000 pounds. The blackened section depicts the percentage of samples intact at the cycles indicated. The sample size was 4 and the test was terminated at $5,000,000$ cycles with four intact samples remaining.

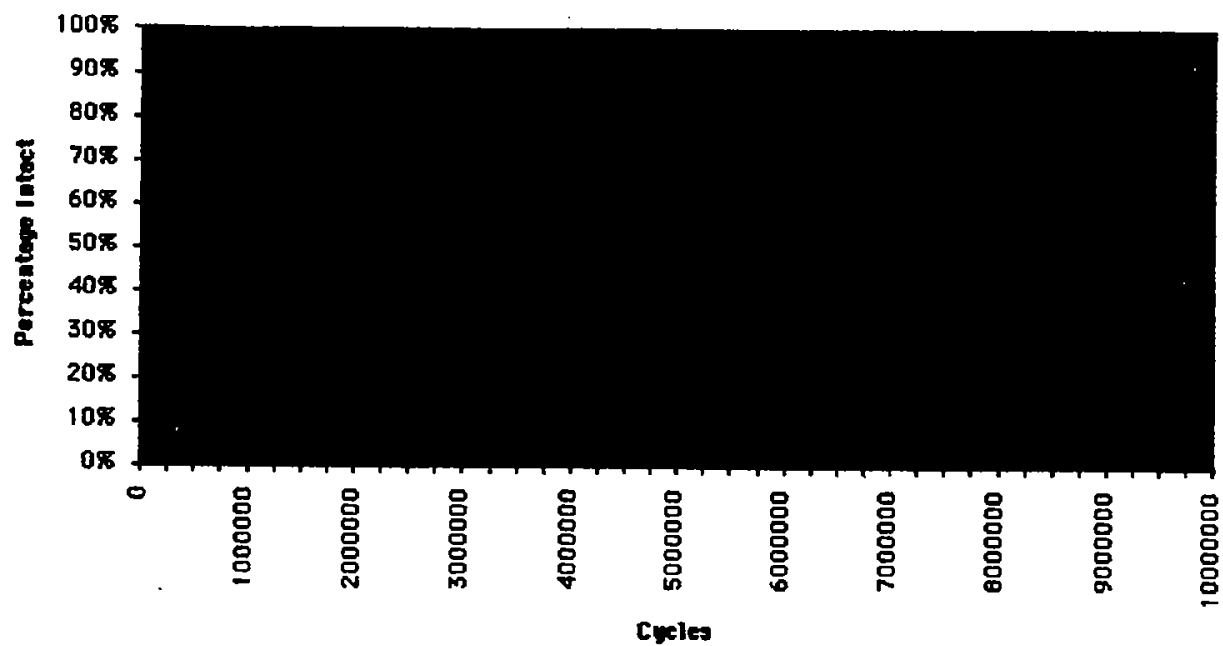

Figure 4q. 7/8" Weldless End Links cycled between 2000 and 6000 pounds. The blackened section depicts the percentage of samples intact at the cycles indicated. The sample size was 4 and the test was terminated at 10,000,000 cycles with four intact samples remaining. 


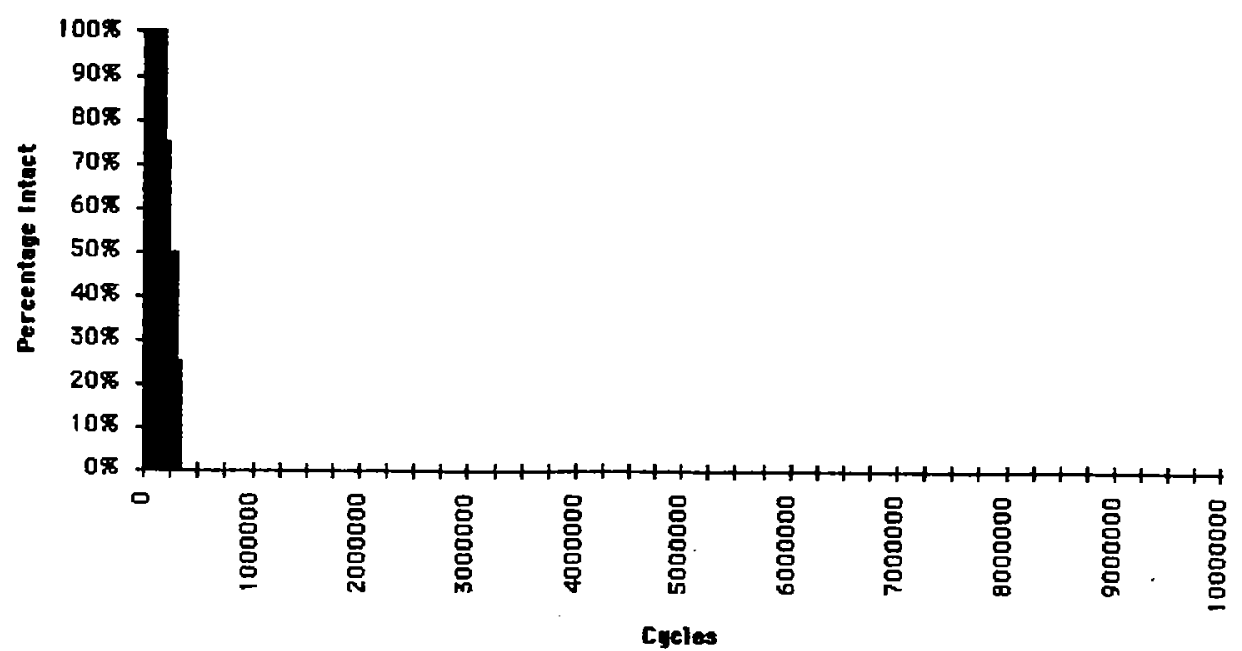

Figure 4r. 7/16" Torque Balanced Wire Rope cycled between 400 and 6800 pounds. The blackened section depicts the percentage of samples intact at the cycles indicated. The sample size was 4 and the test was terminated at 344,320 cycles with no intact samples remaining.

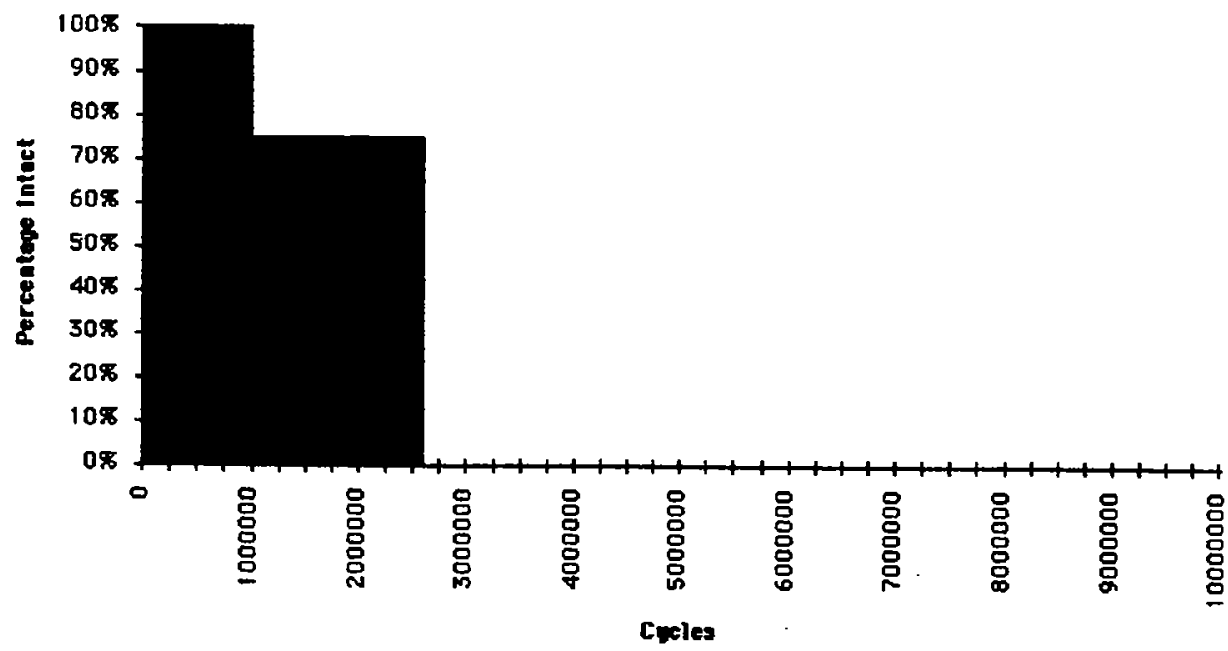

Figure 4s. 7/16" Torque Balanced Wire Rope cycled between 2000 and 6000 pounds. The blackened section depicts the percentage of samples intact at the cycles indicated. The sample size was 4 and the test was terminated at $2,594,840$ cycles with two intact samples remaining. 


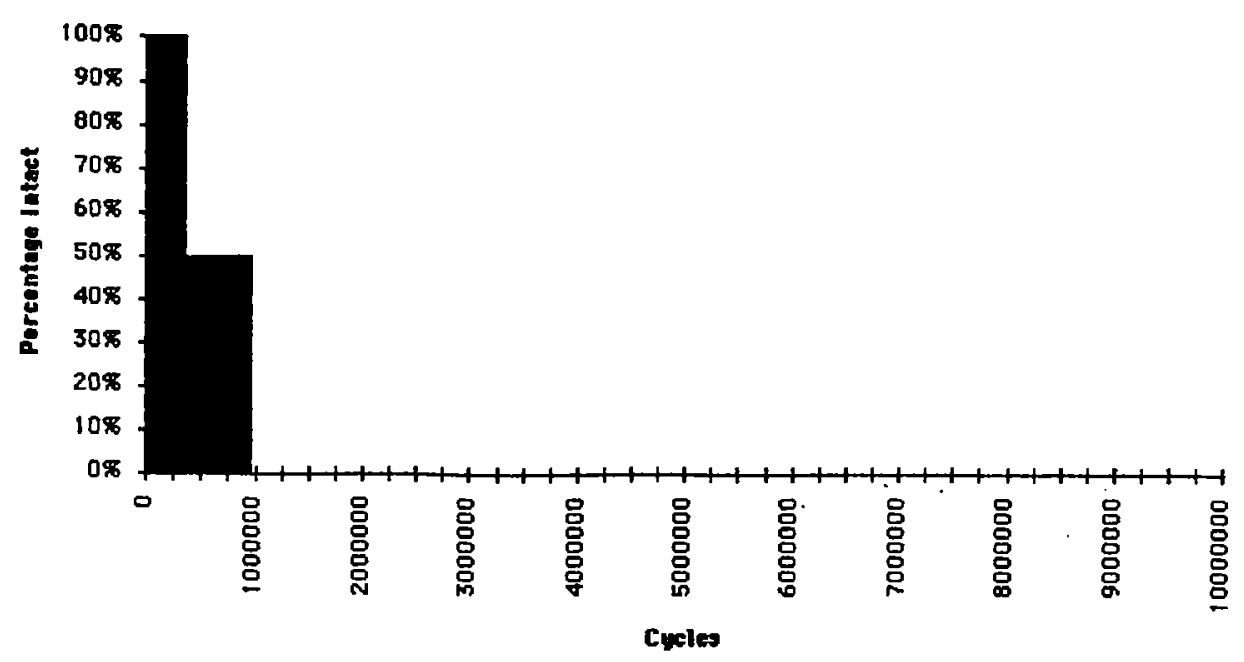

Figure 4t. VMCM-like cage with shortened 3/4" cage rods cycled between 400 and 6800 pounds. The blackened section depicts the percentage of samples intact at the cycles indicated. The sample size was 2 and the test was terminated at 967,080 cycles with no intact samples remaining.

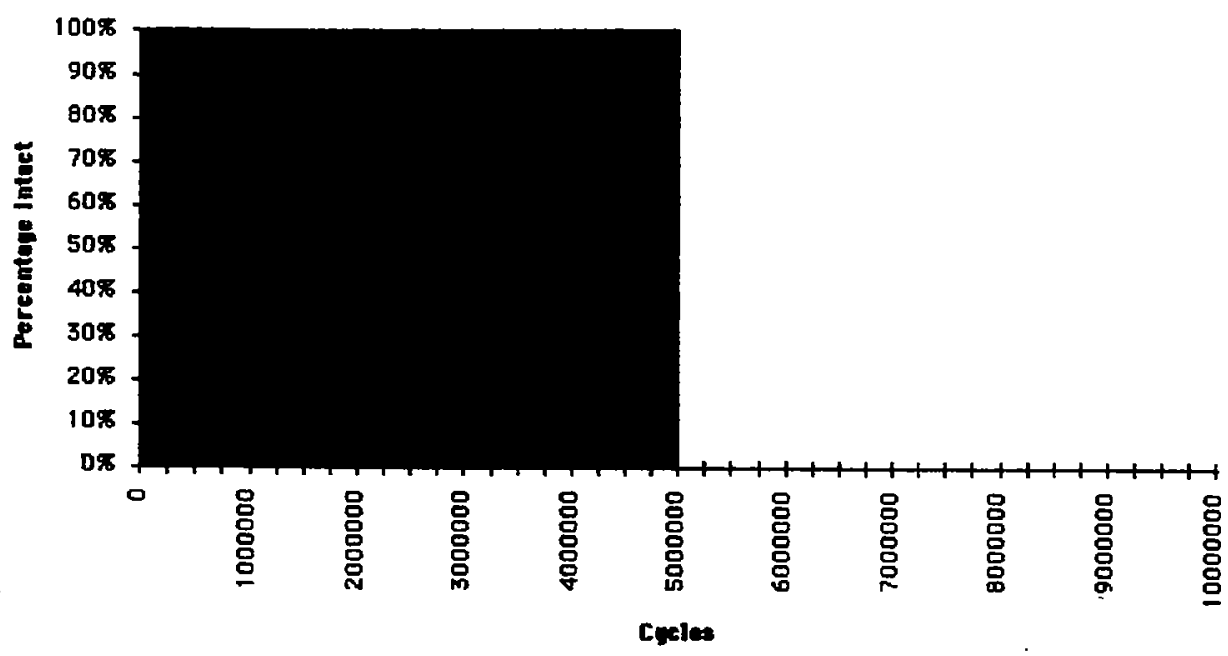

Figure 4u. VMCM-like cage with shortened 3/4" cage rods cycled between 2000 and 6000 pounds. The blackened section depicts the percentage of samples intact at the cycles indicated. The sample size was 2 and the test was terminated at 5,000,000 cycles with two intact samples remaining. 


\section{A. Weldless Links and Shackles}

Due to the expense of conducting the fatigue tests it was difficult to obtain a complete data set whereby all components are tested for all ranges. Figure 5 shows for $5 / 8$ " and 3/4" weldless sling links and 3/4" chain and anchor shackles a plot of cycles to first failure as a function of load range. The combined plot clearly shows the trend that as the load range increases the number of cycles to first failure decreases. A relatively small increase in load range can significantly reduce the number of cycles the component can endure. Take, for example, the 3/4" anchor shackle. By increasing the load range from 6400 pounds to 8400 pounds or an increase of $31 \%$, the number of cycles to first failure dropped from 351,000 to 58,000 or by $83 \%$. Hence, moderate increases in the loading on a mooring can greatly shorten its life expectancy.

The component that failed due to fatigue most often with the fewest number of cycles was the weldless sling link, more commonly known as a pear ring. The weldless sling link was the same component that had failed on the MLML 1989 pilot mooring. The shape of the component is such that the failure always occurs at the end with the large radius of curvature.

The purpose of the weldless sling link in a mooring is to provide places along the mooring where it can be "stopped off" for a variety of reasons such as to insert or remove an instrument, a shot of wire, or as a safe point from which to tow the mooring. A link is usually found between any two adjacent shackles. During deployment and recovery operations an eye hook or similar device on the end of a deck line is snapped into the ring and the line is then secured to a cleat.

The $5 / 8$ " weldless sling links failed as early as 21,250 cycles when loaded between 400 and 7200 pounds. This is equivalent to 1.7 days assuming the waves creating such loads have a 7 second period. The 3/4" weldless sling link did not have a much better showing. In comparing hardware of the same size that was tested at the same load ranges the weldless sling link always failed after fewer cycles.

Since the weldless sling links did not fare well in general, a substitute component was sought. The replacement component had to offer the same capability as the weldless sling link but had to have a greater fatigue life. The 7/8" weldless end link met the necessary size requirements and performed well during the fatigue tests. The 7/8" weldless end links were loaded between 2000 and 6000 pounds and had not experienced a failure after 14 million 


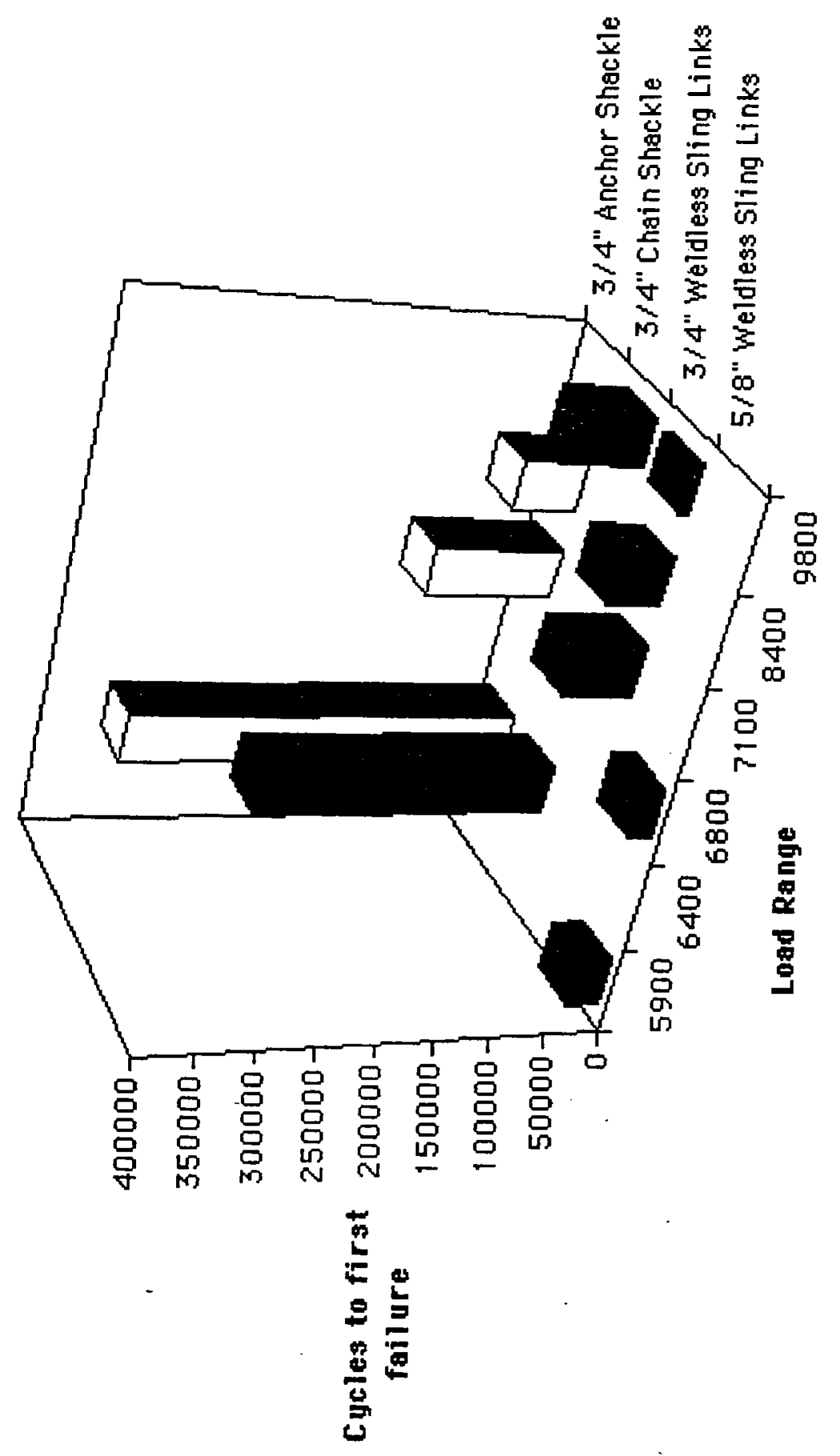

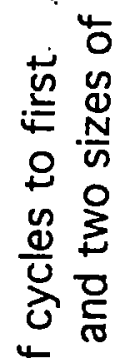

$4 \mathrm{~L}$

ঠั

है 官

당

呆是

음

늠 은

U

\&

은 온

ত

으 으

는

통 웅

宁竞

ఏ

당

เ่ สี

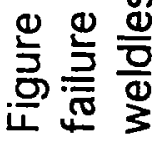


cycles. A smaller size end link would probably have been adequate from a fatigue stand point but the 7/8" size was chosen in order to have a large enough opening to accommodate a hook for the purposes mentioned above. The necessary over-sizing contributed to the improved fatigue life but not without a weight penalty. Four 7/8" weldless sling links survived 4 million load cycles from 2000 to 6000 pounds. Due to the lack of funds these components could not be tested to the extent of the $7 / 8$ " weldless end links. The end links however were the preferred component because they weighed slightly less than the sling links.

\section{S/N Diagram for Weldless Sling Links and Shackles}

Fatigue data are often presented in the form of $S / N$ curves where the cyclic stress amplitude is plotted versus the number of cycles to failure. An S/N curve was generated from the data obtained during the fatigue tests of weldless sling links and safety shackles. Since the failure of any single component in line on a mooring is catastrophic we have taken a conservative approach here and used the number of cycles to the first failure. Seven different load ranges were used in the fatigue tests. The means of the load ranges were all very close to 4000 pounds. To account for the small differences in the mean loads, an adjustment was made to the actual test amplitude $(y)$ using:

$$
y^{*}=y(Y u-4000) /(Y u-T m)
$$

where $y^{*}$ is the effective amplitude, $T m$ is the mean tension, and $Y u$ is the ultimate strength of the given component (Grosenbaugh, 1995). The effective amplitude for a particular test was normalized using the ultimate strength of the component being tested. Figure 6 shows an S/N diagram for both weldless sling links and safety shackles.

Using the test data shown in Figure 6 along with the expression:

$$
N=(y / T)^{q}
$$

which assumes that the number of cycles to failure $(N)$ is related to the amplitude of the dynamic tension $(T)$, we have determined the values of $y$ and $q$ for both types of components. The parameters of $q$ and $y$ are fatigue constants related to the material and geometry of the given mooring component. Sling links can be represented using $y=1.8 Y u$, and $q=3.8$ and safety shackles by $y=1.5 Y u$ and $q=3.8$ where $Y u$ is the ultimate strength of the given component (Grosenbaugh, 1995). 


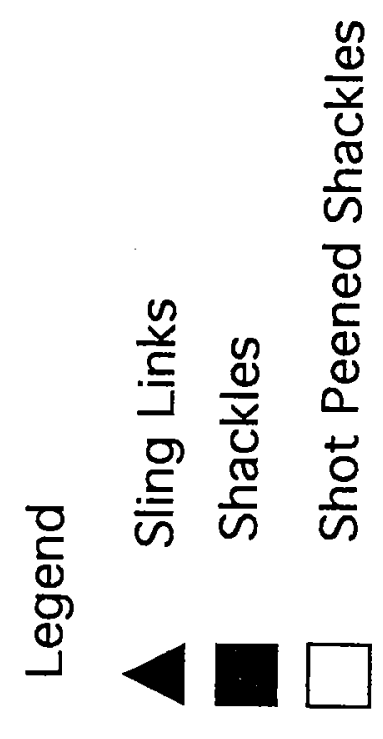

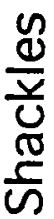
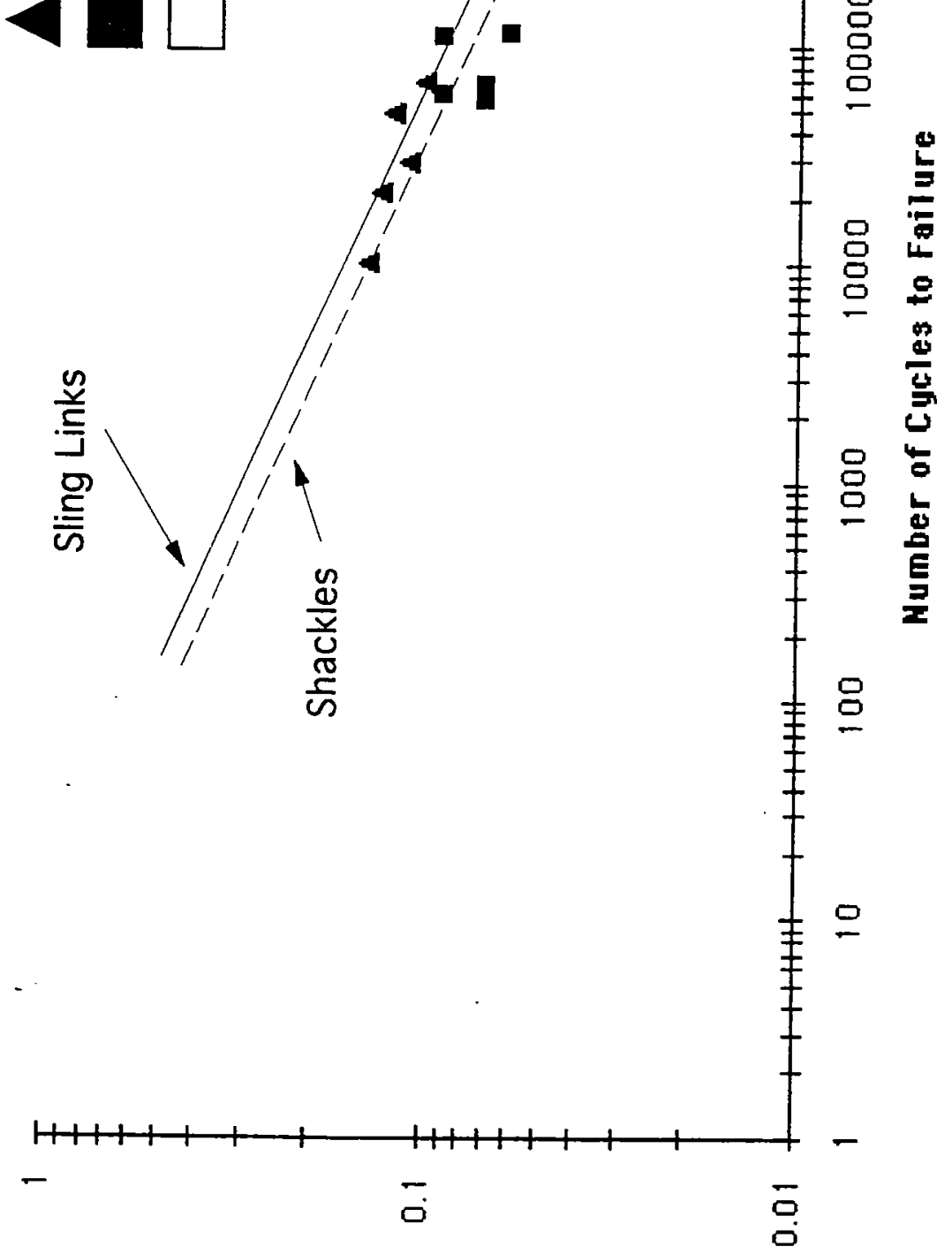

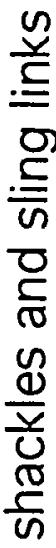

는

हิ

क

$\frac{\pi}{0}$

is

ம

高

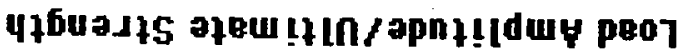




\section{B. Shot Peened Shackles}

Due to the sparse availability of environmental data at a particular mooring site it is not always easy to predict the loading a mooring will experience. To compensate for the unknowns there is a tendency to increase the size of the hardware thereby increasing its load carrying capability. There is, however, a penalty that must be considered. Larger hardware usually weighs more and tends to be more costly. The increase in weight in turn reduces the payload that a mooring can carry. Bale sizes on existing instrumentation also places certain limitations on the size hardware that can be used. Specifying larger hardware can require retrofitting existing equipment with larger bails or possibly require new fabrication of load cages and strength members.

Shot peening is one technique that has been shown to improve the fatigue life of some components without physically increasing their size. During the Arabian Sea fatigue tests the fatigue life of standard galvanized 3/4" chain shackles were compared with shot peened 3/4" non-galvanized shackles.

Thirteen galvanized 3/4" Crosby chain shackles were cycled between 2000 and 6000 pounds. The first failure occurred after 911,320 cycles. One of the thirteen shackles tested was a replacement for a failed component and was still intact when the test was terminated after only accumulating 570,490 cycles. Since it had not failed and did not reach the minimum number of cycles to the first failure we have disregarded it here. Of the remaining 12 shackles five or $42 \%$ failed between 911,320 and $2,972,720$ cycles. The same percentage were intact after $5,000,000$ cycles.

In comparison, eight 3/4" Crosby chain shackles were shot peened and cycled between 2000 and 6000 pounds. The first and only failure occurred after 5,000,000 cycles. Six of the remaining 7 shackles were further tested and all reached 7,727,410 cycles without any failures. Of those six, four were randomly selected and cycled to $14,000,000$ cycles without any failures. Based on these results, the shot peening process seemed to greatly improve the fatigue life of the $3 / 4$ " shackles tested.

A drawback of the shot peening process is that the component should not be galvanized after shot peening. Temperature associated with hot dip galvanizing will stress relieve the component and negate the effects of the shot peening. An alternate means of corrosion protection is therefore needed. A baked-on coating called Xylan is one technique presently 
under test. The application temperature is less than that used during galvanizing and will not affect the shot peening.

\section{Cages}

During the first series of cage testing it became obvious that fabrication specifications are a critical component of repeatable performance. In testing a sample, one hopes that it is representative of the whole. If there is no standard to adhere to then the variability from part to part makes sample test results meaningless. Poorly defined welding techniques, inadequate quality control and testing, and uncertainty about the raw materials used can lead to problems.

Two test cages were fabricated by Stonebridge Corp. using the same drawings previously used to fabricate a number of other VMCM cages. These cages were initially tested from 400 to 6800 pounds and the first failure occurred after just 351,240 cycles. The early failure was attributed to a fabrication technique that was not appropriate for the type of service expected of these cages. Having identified the problem it became clear that the cage fabrication specifications had to be spelled out more clearly. With the help of Stonebridge Corp. the appropriate welding specifications were identified. In addition dye penetrant inspection of all welds was required by a certified inspector and certification of the origin of the material was also required. The specifications adopted for cage fabrication are as follows:

- $\quad$ All cages are to be welded per MIL-STD-2219 Class C. Certification is required.

- All welds are to undergo liquid penetrant inspection per MIL-STD-6866. Certification is required.

- The type 316 stainless steel must conform to MIL Spec number QQ-S-763 for bar stock and MIL Spec number QQ-S-766 or ASTM-A-240 for sheet or plate. Material certification is required.

- All rod stock must be a continuous piece.

- Finished products should be stamped with the welder's certification number and the designation for liquid penetrant inspection.

- Parts will not be accepted for use on moorings without the above mentioned certifications. 
There is, of course, a cost associated with this extra effort; however, it is relatively small when weighed against the total cost of the mooring or the cost of recovering a failed mooring.

Stonebridge also provided assistance in designing a gusset to be welded between the longitudinal members and the end bales to stiffen the cage and improve its fatigue life. Since new cage fabrication was not possible due to financial restraints the gussets were a Band-Aid approach to improve their performance.

Two new test cages were fabricated using all the new specifications and the gussets. These cages were tested between 2000 and 6000 pounds. After 5 million cycles neither cage had failed and the test was terminated. Since the second set of test cages had performed so well, ten existing cages (enough for two Arabian Sea deployments) were retrofitted with gussets and all welds were brought up to the new specification and inspected.

\section{Chain}

Four samples of 3/4" diameter Campbell System 3 proof coil chain were cycled between 2000 and 6000 pounds for a total of 5 million cycles without any failures. Based on these results the System 3 chain was specified for the Arabian Sea surface mooring.

\section{E. Wire Rope}

Two series of wire rope tests were conducted. The number of cycles to failure for the first series of tests cycled between 400 and 6800 pounds seemed surprisingly low. Examination of the failures indicated that the wire had not been properly swaged since the breaks had occurred inside the swage socket. It was attributed to an incorrect filler wire size and to an improper technique used by the operator to work the swage onto the wire. During the second series of wire tests which cycled the wire between 2000 and 6000 pounds the test was terminated after the first two breaks. The first break occurred at 995,470 cycles and the second was at 2,594,840 cycles. Fatigue data from these tests were combined with data collected by the US Steel Corporation (Lucht and Donecker, 1977). The S/N diagram shown in Figure 7 includes both the US Steel data and the WHOI results. The same data analysis techniques used to produce the $\mathrm{S} / \mathrm{N}$ diagram for the weldless sling links and safety shackles were also used for the wire rope S/N diagram.

One difference between the test results obtained for shackles and links and those accumulated for various wire rope tests is that the mean tension for the shackle and link tests were actually close to 4000 pounds. The adjustments made to the test amplitudes using 


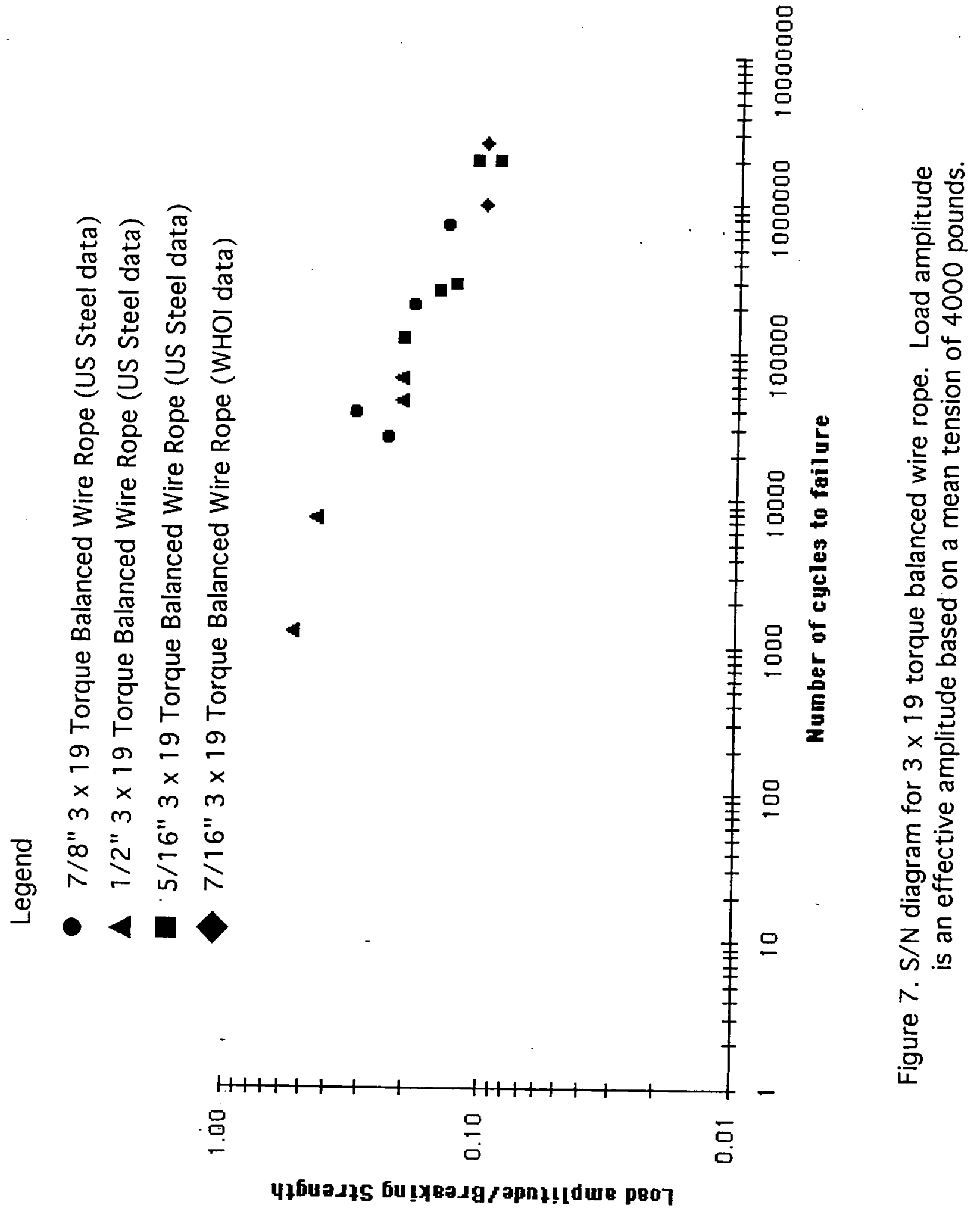


equation 1 were small. However, the wire tests had mean tensions that ranged from 1800 to 19,500 pounds. It is unclear whether applying the same analysis technique used for the shackle and link data is appropriate for the collective wire rope data. We have, therefore, produced two S/N curves for the wire rope. The S/N diagram in Figure 7 uses effective load amplitudes of the various tests based on equation 1. Figure 8 is an $\mathrm{S} / \mathrm{N}$ diagram using the same data but with the actual load amplitude from the specific tests.

\section{Section V: Summary}

Cyclic fatigue testing of in-line mooring components revealed several potential weak links and helped to specify the type of hardware used on the WHOI surface mooring deployed in the Arabian Sea in October 1994 and April 1995. The cyclic fatigue tests conducted as part of the Arabian Sea mooring design effort were as complete as time and funding permitted. Since all tests were conducted in a dry environment one needs to be cautious when applying these results to subsurface applications where corrosion fatigue can be an important factor. It is known that corrosion can reduce the fatigue strength by as much as half (Collins, 1993). Use of a factor of safety between predicted loads and actual component performance helps to offset uncertainties about actual loading and the effects of corrosion.

The use of shot peening mooring hardware, in particular safety chain shackles, was tested as an external treatment to improve component fatigue characteristics. The results of these tests indicated that the shot peened shackles had fatigue properties that were significantly better than non-shot peened shackles. Based on these results shot peened shackles were used throughout the WHOI surface mooring. By utilizing shot peening, shackle size did not have to be increased to acquire better fatigue properties at the expected loads. Larger shackles would have meant costly modifications to existing instrument load cages so as to accommodate their larger dimensions. Had a larger size shackle been needed both financial and design considerations would have suffered. A larger size component would have been more costly and would have weighed more which would have reduced the load carrying capacity of the mooring.

The superior performance of the weldless end links during the fatigue tests resulted in their replacing weldless sling links (also known as pear rings) throughout the Arabian Sea mooring. Tests on wire rope reinforced the need for careful adherence to swaging 


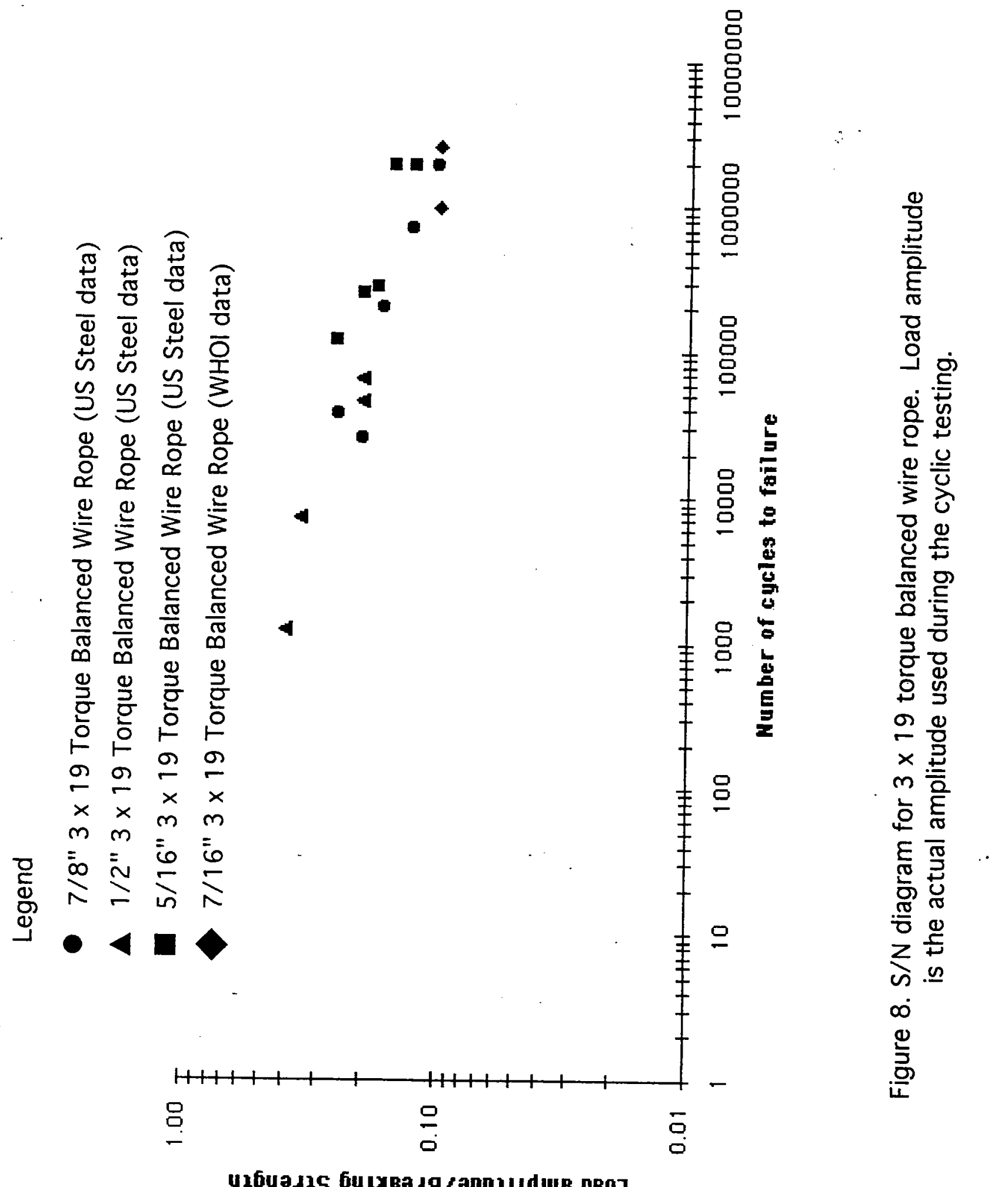

4ұ6uast5 6u Lxвa.g/apnł! [dus pBo] 
specifications. Chain testing indicated that it was adequate for use on the Arabian Sea mooring.

The testing of VMCM load cages was particularly revealing. Loosely defined welding specifications coupled with a marginal end bale design resulted in fabricated products that did not perform well during the fatigue tests. Welding techniques and procedures were reviewed and a revised set of specifications were written. Two test cages fabricated with the new welding specification and with a modified end bale design were tested. The test cages performed well during the cyclic fatigue tests. All existing VMCM cages used on the WHOI Arabian Sea mooring were retrofitted with the modified end bale and all welds were brought up to the new specifications. All new fabrication of cages and strength members incorporated the new end bale and revised welding specifications.

The fatigue test results from shackles, and sling links were compiled to generate a $S / N$ diagram that can be used in conjunction with future design efforts. In addition the wire rope tests results were compiled with historical wire rope data from US Steel to generate a $S / N$ diagram for torque balanced $3 \times 19$ wire rope.

The information gained from these cyclic fatigue tests is applicable wherever hardware is subjected to dynamic loads. Any structure subject to surface waves, whether it be in a moored or towed application, is stressed both statically and dynamically. Little information is currently available about the fatigue characteristics of hardware of this type. Hardware manufacturers are concerned primarily with the static load carrying capability of their products. Static loads are, however, only one part of the problem. Rarely does a manufacturer conduct any fatigue analysis of their product for a duration typical of mooring applications. Failures can occur quite rapidly even when components are subjected to cyclic loads which may be considerably less than the component's ultimate strength. The magnitude of the static and dynamic loads, duration and component fatigue endurance are important considerations which cannot be ignored in the design process. 


\section{Acknowledgments}

The authors wish to thank Mark Grosenbaugh and Nathan Ulrich for the guidance they provided during the fatigue testing program and for their assistance in the design of the Arabian Sea surface mooring. The cooperation of the WHOI rigging shop, under the direction of Dave Simoneau, in providing hardware and test samples is greatly appreciated. Special thanks are extended to Will Ostrom who oversaw the VMCM end bale redesign and took care of the logistics of getting samples to and from the testing lab. We sincerely thank Nancy Brink and Mary Ann Lucas for their help in preparing this report.

This work was supported by the Office of Naval Research Grant No. N00014-93-1-0704.

\section{References}

Collins, J. A., 1993. Failure of Materials in Mechanical Design. John Wiley and Sons, Inc., New York, $654 \mathrm{pp}$.

Grosenbaugh, Mark A., 1995. Designing oceanographic surface moorings to withstand fatigue. Journal of Atmospheric and Oceanic Technology, 12, 1101-1110.

Lucht, W. A., and F. W. Donecker, 1977. Factors affecting wire rope life in a marine environment. This paper was presented at the 9th annual Offshore Technology Conference in Houston Texas May 2-5, 1977, OTC 2924 No. 77, pages 361-368.

Plueddemann, Albert J., Robert A. Weller, Malgorzata Stramska, Tommy Dickey, and John Marra, 1995. Vertical structure of the upper ocean during the Marine Light-Mixed Layers experiment. Journal of Geophysical Research, 100(C4), 6605-6619. 


\section{Appendix 1: Fatigue Test Data}

The data collected during the fatigue tests appear in Appendix 1. It has been grouped by component, size and loading. For example, 3/4" Crosby anchor shackles tested between 400 and 6800 pounds are separate from 3/4" Crosby anchor shackles tested between 400 and 7500 pounds. Within each group information about each component tested includes the maximum number of cycles attained, the condition of the component at the maximum number of cycles, and the specific test from which the data were obtained. For example, while testing VMCM cages there were a number of 3/4" anchor shackles in line as well. Some test data for the 3/4" anchor shackles will therefore indicate it originated from the cage tests. 
5/8" Anchor Shackles

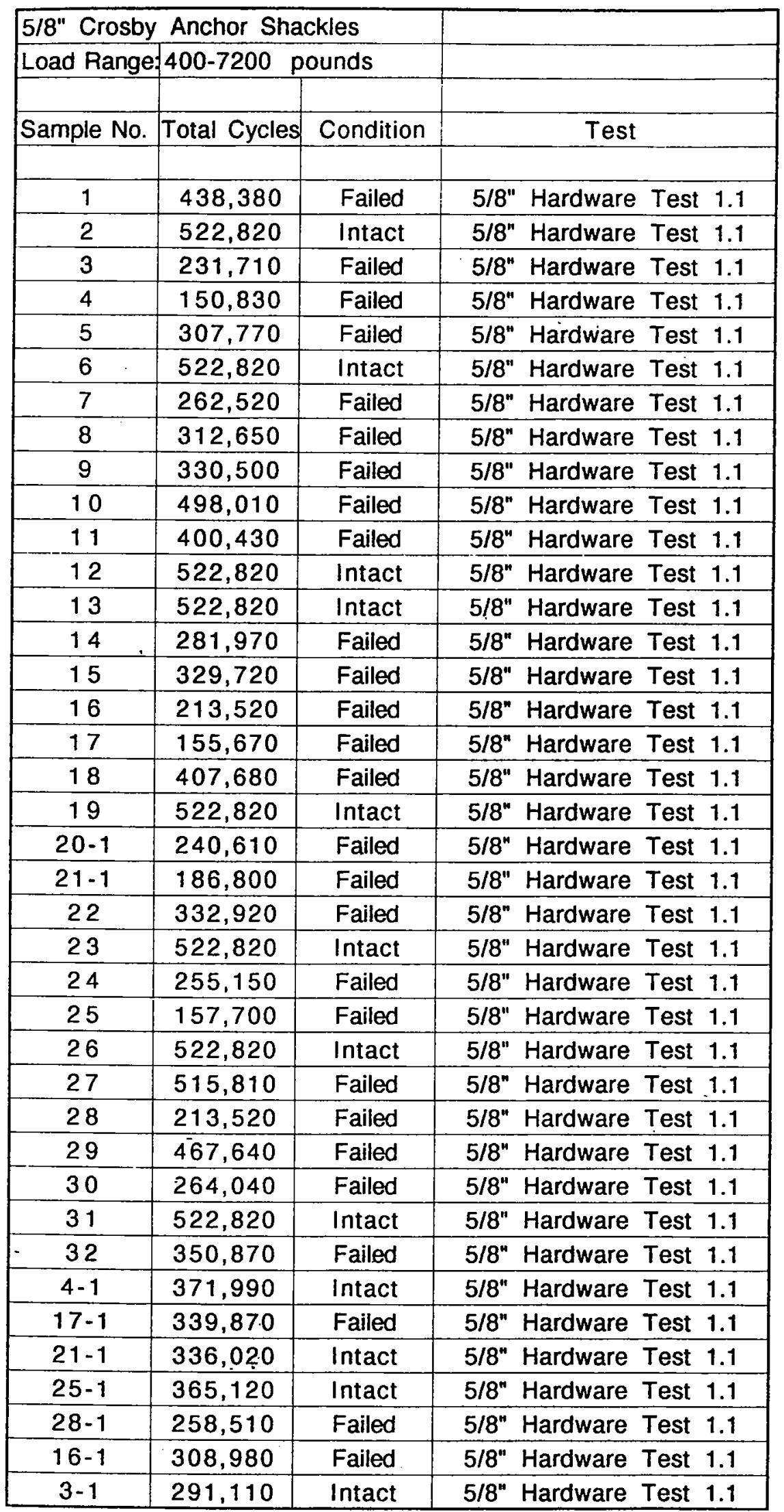


5/8" Anchor Shackles

\begin{tabular}{|c|c|c|c|c|c|}
\hline $20-1$ & 282,210 & Intact & $5 / 8^{\prime \prime}$ & Hardware Test & 1.1 \\
\hline $24-1$ & 267,670 & Failed & $5 / 8^{\prime \prime}$ & Hardware Test & 1.1 \\
\hline $7-1$ & 260,300 & Failed & $5 / 8 "$ & Hardware Test & 1.1 \\
\hline $30-1$ & 226,490 & Failed & $5 / 8^{\prime \prime}$ & Hardware Test & 1.1 \\
\hline 14-1 & 176,930 & Failed & $5 / 8^{\prime \prime}$ & Hardware Test & 1.1 \\
\hline $5-1$ & 149,410 & Failed & $5 / 8^{\prime \prime}$ & Hardware Test & 1.1 \\
\hline $8-1$ & 210170 & Intact & $5 / 8^{\prime \prime}$ & Hardware Test & 1.1 \\
\hline $15-1$ & 124,480 & Failed & $5 / 8^{\prime \prime}$ & Hardware Test & 1.1 \\
\hline $9-1$ & 192320 & Intact & $5 / 8^{\prime \prime}$ & Hardware Test & 1.1 \\
\hline $22-1$ & 115,160 & Failed & $5 / 8^{\prime \prime}$ & Hardware Test & 1.1 \\
\hline $32-1$ & 171950 & Intact & $5 / 8^{\prime \prime}$ & Hardware Test & 1.1 \\
\hline $11-1$ & 122390 & Intact & $5 / 8 "$ & Hardware Test & 1.1 \\
\hline 18-1 & 115140 & Intact & $5 / 8^{\prime \prime}$ & Hardware Test & 1.1 \\
\hline $1-1$ & 84440 & Intact & $5 / 8^{n}$ & Hardware Test & 1.1 \\
\hline $22-2$ & 74740 & Intact & $5 / 8^{\prime \prime}$ & Hardware Test & 1.1 \\
\hline $15-2$ & 68620 & Intact & $5 / 8^{\prime \prime}$ & Hardware Test & 1.1 \\
\hline $5-2$ & 65640 & Intact & $5 / 8^{\prime \prime}$ & Hardware Test & 1.1 \\
\hline $14-2$ & 63920 & Intact & $5 / 8^{\prime \prime}$ & Hardware Test & 1.1 \\
\hline $29-1$ & 55180 & Intact & $5 / 8^{\prime \prime}$ & Hardware Test & 1.1 \\
\hline $28-2$ & 50790 & Intact & $5 / 8^{\prime \prime}$ & Hardware Test & 1.1 \\
\hline $30-2$ & 32290 & Intact & $5 / 8^{n}$ & Hardware Test & 1.1 \\
\hline $17-2$ & 27280 & Intact & $5 / 8^{\prime \prime}$ & Hardware Test & 1.1 \\
\hline $10-1$ & 24810 & Intact & $5 / 8 "$ & Hardware Test & 1.1 \\
\hline $27-1$ & 7010 & Intact & $5 / 8^{\prime \prime}$ & Hardware Test & 1.1 \\
\hline \multirow[t]{2}{*}{$16-2$} & 320 & Intact & $5 / 8^{\prime \prime}$ & Hardware Test & 1.1 \\
\hline & & & & & . \\
\hline \multicolumn{6}{|c|}{ 5/8" Crosby Anchor Shackles } \\
\hline Load Range & \multicolumn{2}{|c|}{00 pounds } & & & \\
\hline Sample No. & Total Cycles & Condition & & Test & \\
\hline & & . & & & \\
\hline 1 & 313,210 & Failed & $5 / 8 "$ & Hardware Test & 1.2 \\
\hline 2 & 582,680 & Intact & $5 / 8^{\prime \prime}$ & Hardware Test & 1.2 \\
\hline 3 & 442,290 & Failed & $5 / 8^{\prime \prime}$ & Hardware Test & 1.2 \\
\hline 4 & 380,190 & Failed & $5 / 8^{\prime \prime}$ & Hardware Test & 1.2 \\
\hline 5 & 112,280 & Failed & $5 / 8^{\prime \prime}$ & Hardware Test & 1.2 \\
\hline 6 & 582,680 & Intact & $5 / 8^{\prime \prime}$ & Hardware Test & 1.2 \\
\hline 7 & 299,440 & Failed & $5 / 8^{\prime \prime}$ & Hardware Test & 1.2 \\
\hline 8 & 178,140 & Failed & $5 / 8^{\prime \prime}$ & Hardware Test & 1.2 \\
\hline 9 & 136,170 & Failed & $5 / 8^{\prime \prime}$ & Hardware Test & 1.2 \\
\hline 10 & 582,680 & Intact & $5 / 8^{\prime \prime}$ & Hardware Test & 1.2 \\
\hline 11 & 582,680 & Intact & $5 / 8^{\prime \prime}$ & Hardware Test & 1.2 \\
\hline
\end{tabular}


5/8" Anchor Shackles

\begin{tabular}{|c|c|c|c|c|c|}
\hline 12 & 582,680 & Intact & $5 / 8^{\prime \prime}$ & Hardware Test & 1.2 \\
\hline 13 & 442,290 & Failed & $5 / 8^{\prime \prime}$ & Hardware Test & 1.2 \\
\hline 14 & 225,210 & Failed & $5 / 8^{n}$ & Hardware Test & 1.2 \\
\hline 15 & 196,680 & Failed & $5 / 8^{\prime \prime}$ & Hardware Test & 1.2 \\
\hline 16 & 147,680 & Failed & $5 / 8^{\prime \prime}$ & Hardware Test & 1.2 \\
\hline 17 & 226,150 & Failed & $5 / 8^{\prime \prime}$ & Hardware Test & 1.2 \\
\hline 18 & 582,680 & Intact & $5 / 8^{\prime \prime}$ & Hardware Test & 1.2 \\
\hline 19 & 582,680 & Intact & $5 / 8^{n}$ & Hardware Test & 1.2 \\
\hline 20 & 404,920 & Failed & $5 / 8^{\prime \prime}$ & Hardware Test & 1.2 \\
\hline 21 & 572,790 & Failed & $5 / 8^{\prime \prime}$ & Hardware Test & 1.2 \\
\hline 22 & 582,680 & Intact & $5 / 8^{\prime \prime}$ & Hardware Test & 1.2 \\
\hline 23 & 165,480 & Failed & $5 / 8 "$ & Hardware Test & 1.2 \\
\hline 24 & 582,680 & Intact & $5 / 8$ & Hardware Test & 1.2 \\
\hline 25 & 346,870 & Failed & $5 / 8^{\prime \prime}$ & Hardware Test & 1.2 \\
\hline 26 & 158,010 & Failed & $5 / 8^{\prime \prime}$ & Hardware Test & 1.2 \\
\hline 27 & 178,700 & Failed & $5 / 8^{\prime \prime}$ & Hardware Test & 1.2 \\
\hline 28 & 537,130 & Failed & $5 / 8^{n}$ & Hardware Test & 1.2 \\
\hline 29 & 582,680 & Intact & $5 / 8^{\prime \prime}$ & Hardware Test & 1.2 \\
\hline 30 & 158,910 & Failed & $5 / 8^{\prime \prime}$ & Hardware Test & 1.2 \\
\hline 31 & 456,910 & Failed & $5 / 8^{\prime \prime}$ & Hardware Test & 1.2 \\
\hline 32 & 367,610 & Failed & $5 / 8^{\prime \prime}$ & Hardware Test & 1.2 \\
\hline $5-1$ & 190,940 & Failed & $5 / 8^{\prime \prime}$ & Hardware Test & 1.2 \\
\hline $9-1$ & 292,420 & Failed & $5 / 8^{\prime \prime}$ & Hardware Test & 1.2 \\
\hline $16-1$ & 154,240 & Failed & $5 / 8^{\prime \prime}$ & Hardware Test & 1.2 \\
\hline $26-1$ & 68,350 & Failed & $5 / 8^{\prime \prime}$ & Hardware Test & 1.2 \\
\hline $30-1$ & 423,770 & Intact & $5 / 8^{\prime \prime}$ & Hardware Test & 1.2 \\
\hline 23-1 & 417,200 & Intact & $5 / 8^{n}$ & Hardware Test & 1.2 \\
\hline $8-1$ & 374,070 & Failed & $5 / 8^{\prime \prime}$ & Hardware Test & 1.2 \\
\hline $27-1$ & 403,980 & Intact & $5 / 8 "$ & Hardware Test & 1.2 \\
\hline $15-1$ & 380,220 & Failed & $5 / 8^{\prime \prime}$ & Hardware Test & 1.2 \\
\hline 14-1 & 357,470 & Intact & $5 / 8^{\prime \prime}$ & Hardware Test & 1.2 \\
\hline $17-1$ & 356,530 & Intact & $5 / 8^{\prime \prime}$ & Hardware Test & 1.2 \\
\hline $26-2$ & 356,320 & Intact & $5 / 8^{n}$ & Hardware Test & 1.2 \\
\hline $7-1$ & 283,240 & Intact & $5 / 8^{\prime \prime}$ & Hardware Test & 1.2 \\
\hline $16-2$ & 235,460 & Failed & $5 / 8 "$ & Hardware Test & 1.2 \\
\hline $6-1$ & 154,170 & Failed & $5 / 8 "$ & Hardware Test & 1.2 \\
\hline $1-1$ & 269,470 & Intact & $5 / 8^{\prime \prime}$ & Hardware Test & 1.2 \\
\hline $25-1$ & 235,810 & Failed & $5 / 8^{\prime \prime}$ & Hardware Test & 1.2 \\
\hline $32-1$ & $215,07.0$ & Intact & $5 / 8^{\prime \prime}$ & Hardware Test & 1.2 \\
\hline $4-1$ & 202,490 & Intact & $5 / 8^{\prime \prime}$ & Hardware Test & 1.2 \\
\hline $20-1$ & 75,470 & Failed & $5 / 8^{\prime \prime}$ & Hardware Test & 1.2 \\
\hline $9-2$ & 154,090 & Intact & $5 / 8^{\prime \prime}$ & Hardware Test & 1.2 \\
\hline $13-1$ & 121,530 & Failed & $5 / 8^{\prime \prime}$ & Hardware Test & 1.2 \\
\hline $3-1$ & 140,390 & Intact & $5 / 8^{n}$ & Hardware . Test & 1.2 \\
\hline
\end{tabular}


5/8" Anchor Shackles

\begin{tabular}{|c|c|c|c|c|c|}
\hline 31-1 & 125,770 & Intact & 5/8" Hardware & Test & 1.2 \\
\hline $6 \cdot 2$ & 117,940 & Intact & 5/8" Hardware & Test & 1.2 \\
\hline $20-2$ & 102,290 & Intact & 5/8" Hardware & Test & 1.2 \\
\hline 28-1 & 45,550 & Intact & 5/8" Hardware & Test & 1.2 \\
\hline $16-3$ & 45,300 & Intact & 5/8" Hardware & Test & 1.2 \\
\hline $8-2$ & 30,470 & Intact & 5/8" Hardware & Test & 1.2 \\
\hline $13-2$ & 18,860 & Intact & 5/8" Hardware & Test & 1.2 \\
\hline $21-1$ & 9,890 & Intact & 5/8" Hardware & Test & 1.2 \\
\hline $15-2$ & 5,780 & Intact & 5/8" Hardware & Test & 1.2 \\
\hline
\end{tabular}


5/8" SP ANCHOR SHACKLES

\begin{tabular}{|c|c|c|c|}
\hline \multicolumn{5}{|l}{ 5/8" Shot Peened Crosby Anchor Shackles } \\
\hline & & & \\
\hline & & & \\
\hline & & & \\
\hline & & & \\
\hline Sample No. & Total Cycles & Condition & Test \\
\hline & & & \\
\hline 1 & $1,207,640$ & Failed & Cages \#2 \\
\hline 2 & $5,000,000$ & Intact & Cages \#2 \\
\hline 3 & $2,727,410$ & Intact & Cages \#2 \\
\hline 4 & $2,727,410$ & Failed & Cages \#2 \\
\hline 1.1 & 555,210 & Failed & Cages \#2 \\
\hline 1.2 & $3,237,150$ & Intact & Cages \#2 \\
\hline & & & \\
\hline & & & \\
\hline & & & \\
\hline & & & \\
\hline
\end{tabular}




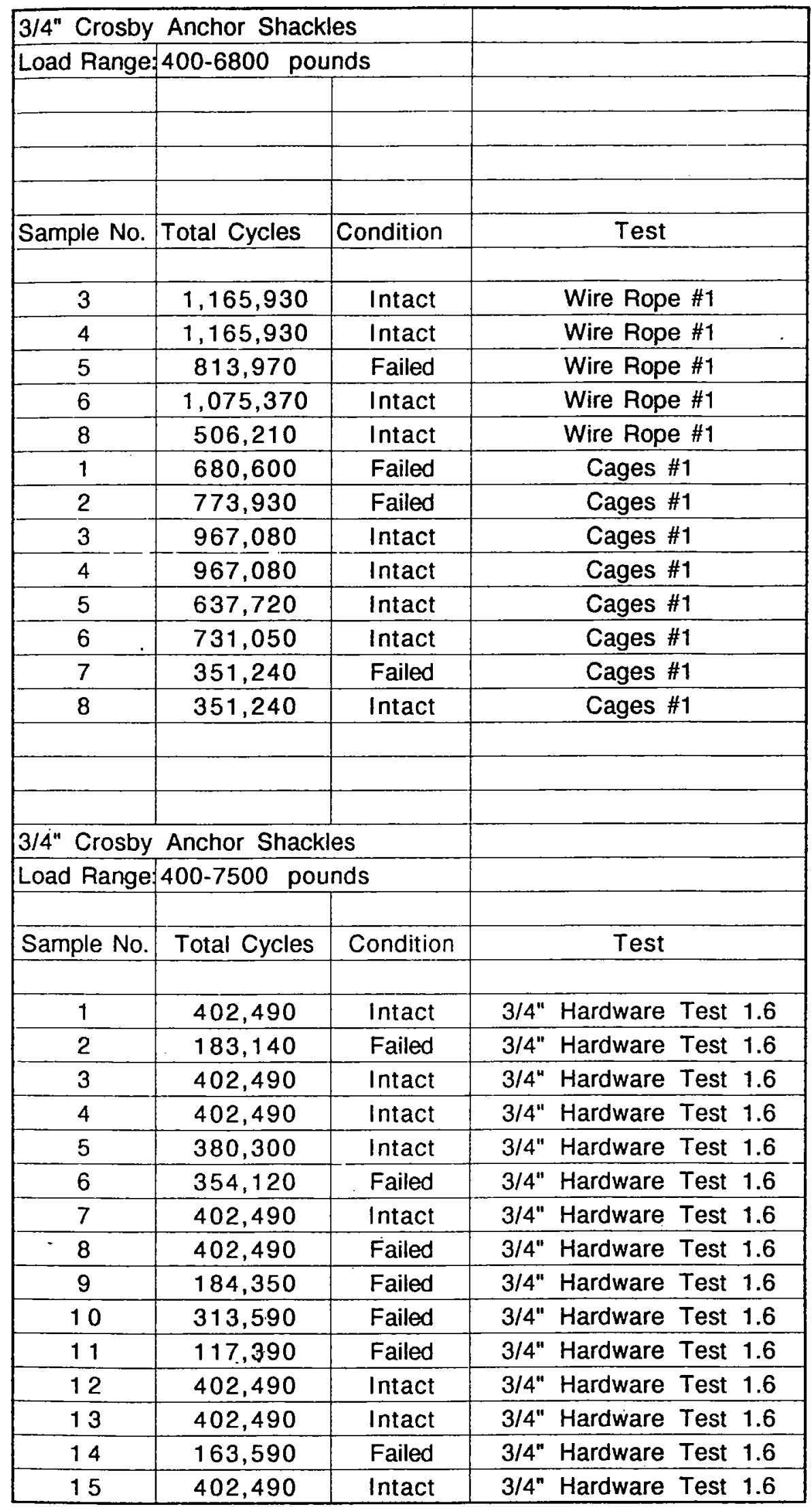


3/4" Anchor SHACKLES .4-6.8

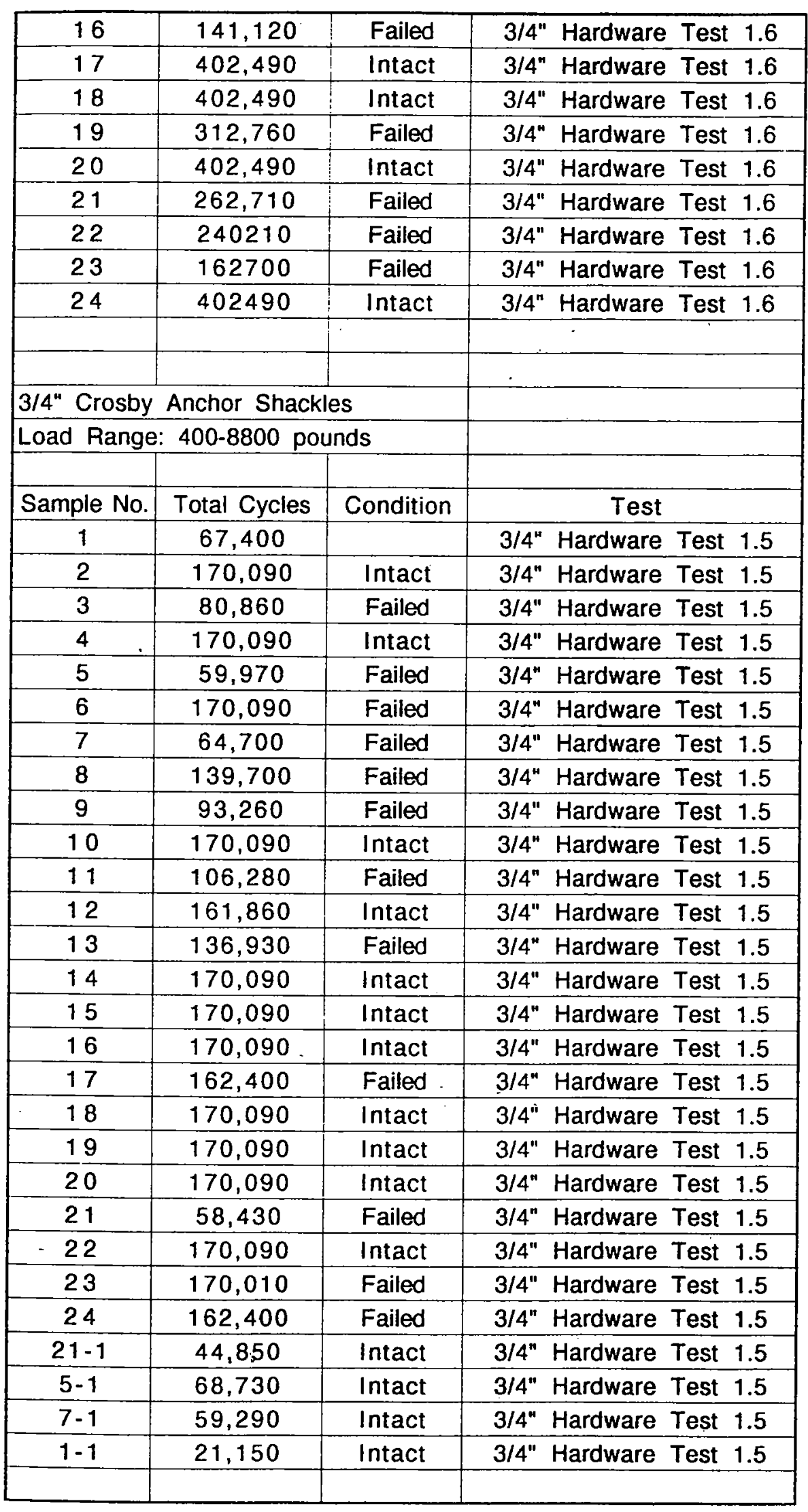




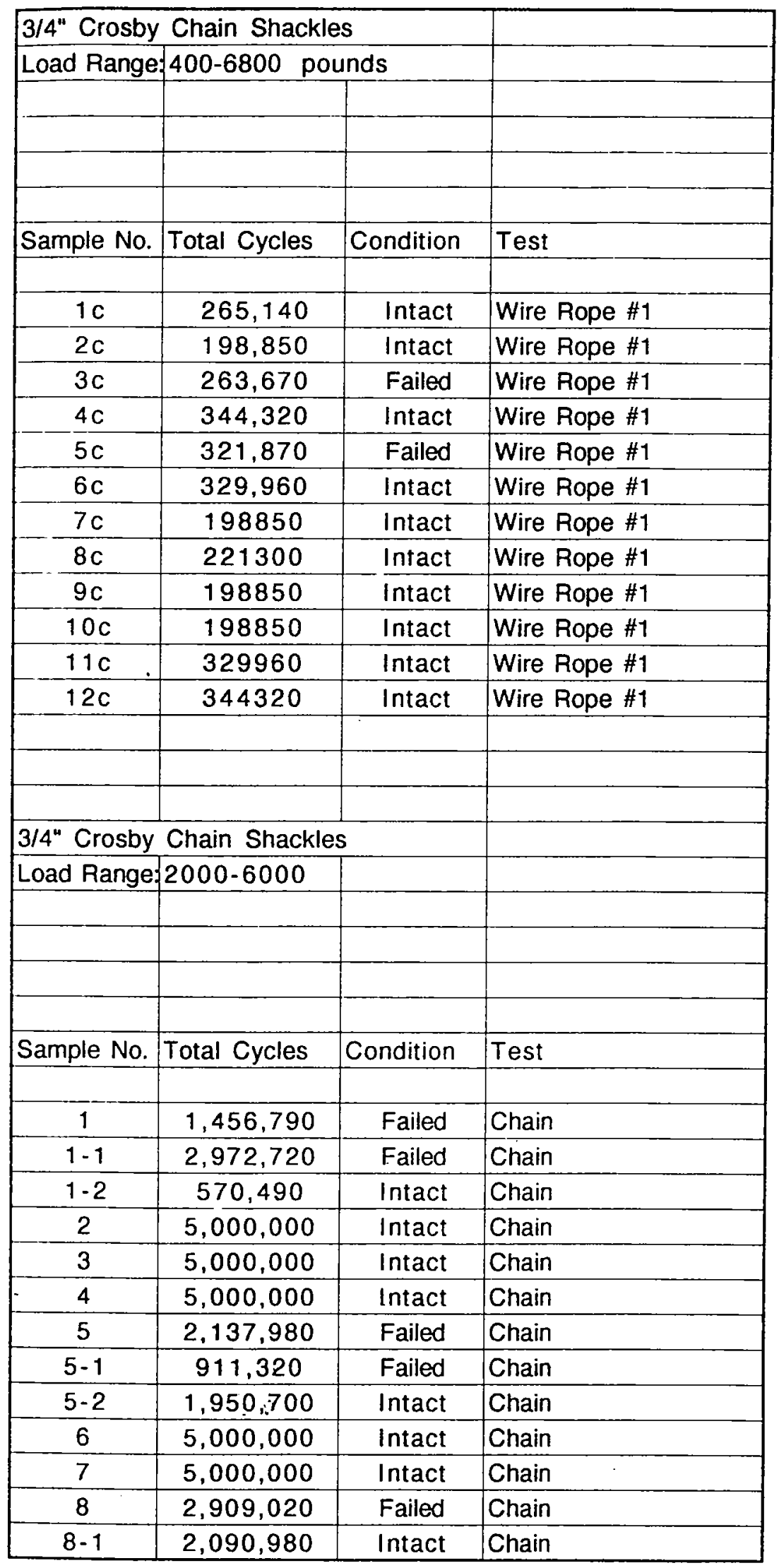




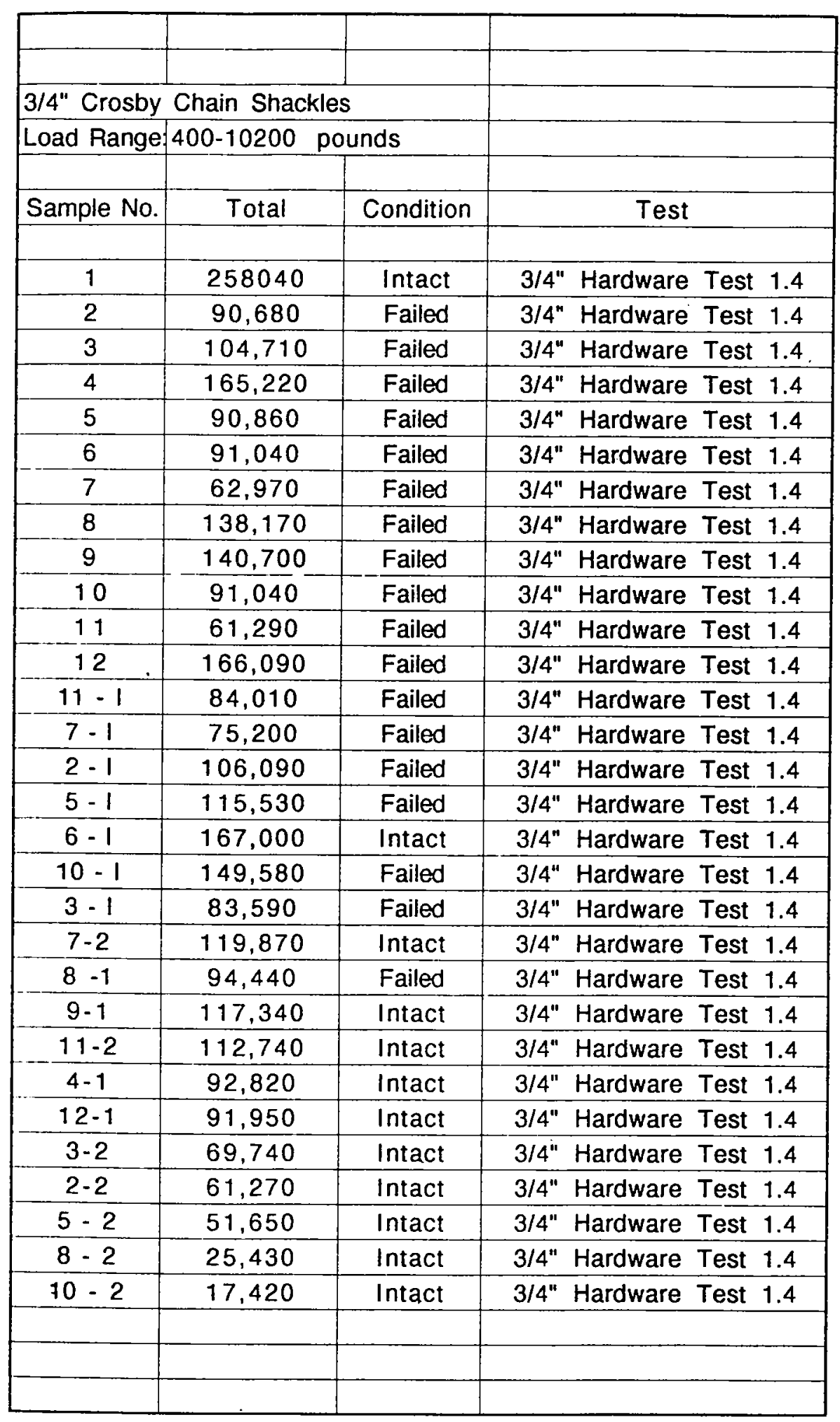




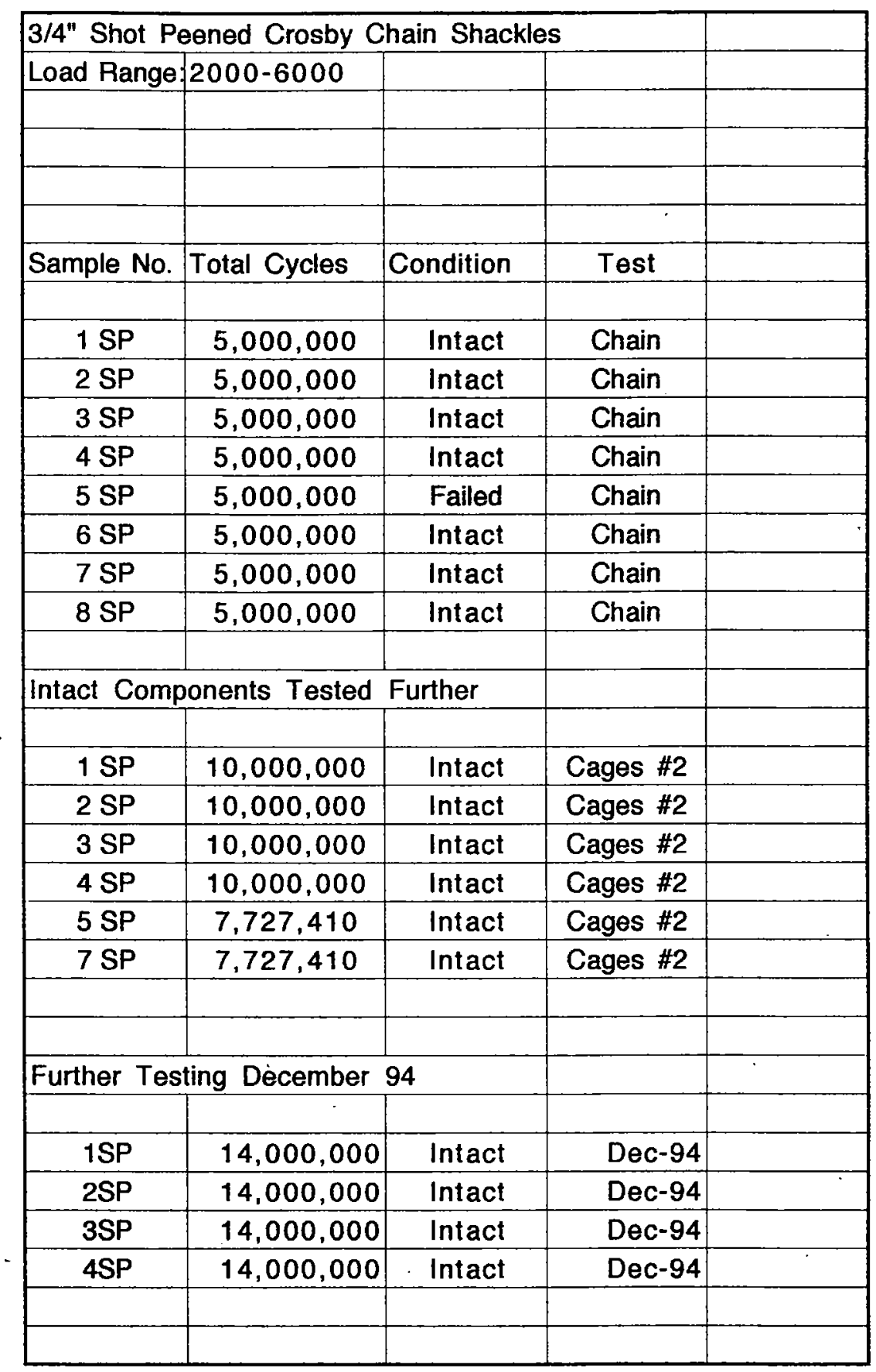




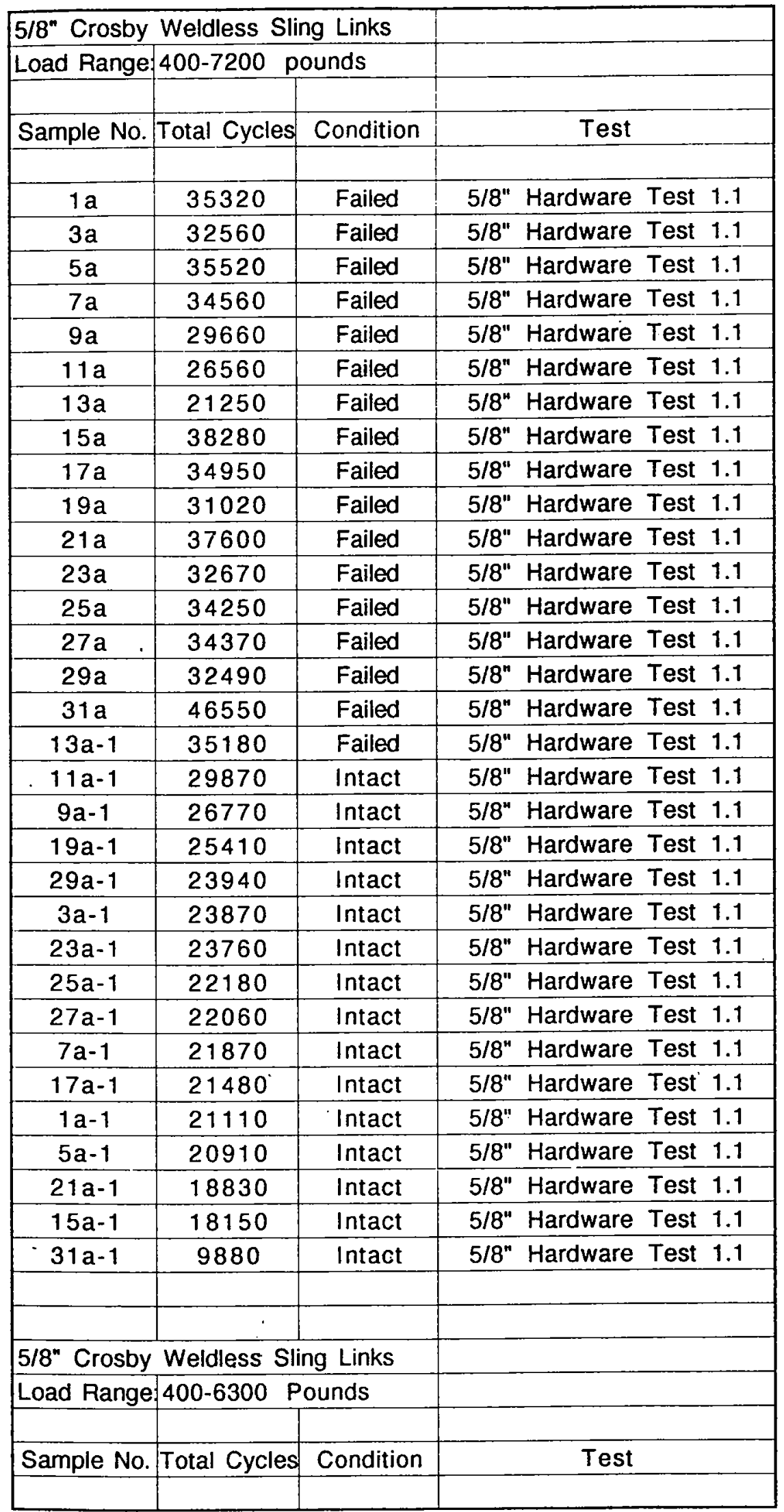




\begin{tabular}{|c|c|c|c|c|c|}
\hline $1 \mathrm{a}$ & 47330 & Failed & $5 / 8^{\prime \prime}$ & Hardware & Test 1.2 \\
\hline $3 a$ & 59210 & Failed & $5 / 8^{\prime \prime}$ & Hardware & Test 1.2 \\
\hline $5 a$ & 54810 & Failed & $5 / 8^{\prime \prime}$ & Hardware & Test 1.2 \\
\hline $7 \mathrm{a}$ & 43290 & Failed & $5 / 8^{\prime \prime}$ & Hardware & Test 1.2 \\
\hline $9 a$ & 106090 & Failed & $5 / 8^{\prime \prime}$ & Hardware & Test 1.2 \\
\hline $11 \mathrm{a}$ & 35450 & Failed & $5 / 8^{\prime \prime}$ & Hardware & Test 1.2 \\
\hline $13 a$ & 50980 & Failed & $5 / 8 "$ & Hardware & Test 1.2 \\
\hline $15 a$ & 74060 & Failed & $5 / 8^{\prime \prime}$ & Hardware & Test 1.2 \\
\hline $17 a$ & 40980 & Failed & $5 / 8^{\prime \prime}$ & Hardware & Test 1.2 \\
\hline $19 a$ & 42850 & Failed & $5 / 8^{\prime \prime}$ & Hardware & Test 1.2 \\
\hline $21 a$ & 53020 & Failed & 5/8." & Hardware & Test 1.2 \\
\hline $23 a$ & 37030 & Failed & $5 / 8^{\prime \prime}$ & Hardware & Test 1.2 \\
\hline $25 a$ & 44120 & Failed & $5 / 8^{\prime \prime}$ & Hardware & Test 1.2 \\
\hline $27 a$ & 126400 & Failed & $5 / 8^{\prime \prime}$ & Hardware & Test 1.2 \\
\hline $29 a$ & 55900 & Failed & $5 / 8^{\prime \prime}$ & Hardware & Test 1.2 \\
\hline $31 a$ & 41380 & Failed & $5 / 8^{\prime \prime}$ & Hardware & Test 1.2 \\
\hline $11 \mathrm{a}-1$ & 41940 & Failed & $5 / 8^{\prime \prime}$ & Hardware & Test 1.2 \\
\hline $23 a-1$ & 62600 & Failed & $5 / 8^{\prime \prime}$ & Hardware & Test 1.2 \\
\hline $17 a-1$ & 29280 & Failed & $5 / 8^{\prime \prime}$ & Hardware & Test 1.2 \\
\hline $31 \mathrm{a}-1$ & 47090 & Failed & $5 / 8^{\prime \prime}$ & Hardware & Test 1.2 \\
\hline $19 a-1$ & 40870 & Failed & $5 / 8^{\prime \prime}$ & Hardware & Test 1.2 \\
\hline $7 a-1$ & 29720 & Failed & $5 / 8^{\prime \prime}$ & Hardware & Test 1.2 \\
\hline $25 a-1$ & 42260 & Failed & $5 / 8^{\prime \prime}$ & Hardware & Test 1.2 \\
\hline $1 a-1$ & 74050 & Intact & $5 / 8^{\prime \prime}$ & Hardware & Test 1.2 \\
\hline $13 a-1$ & 59680 & Failed & $5 / 8 "$ & Hardware & Test 1.2 \\
\hline $21 a-1$ & 55640 & Failed & $5 / 8^{n}$ & Hardware & Test 1.2 \\
\hline $5 a-1$ & 66570 & Intact & $5 / 8^{\prime \prime}$ & Hardware & Test 1.2 \\
\hline $29 a-1$ & 65480 & Failed & $5 / 8^{\prime \prime}$ & Hardware & Test 1.2 \\
\hline $3 a-1$ & 65920 & Failed & $5 / 8^{\prime \prime}$ & Hardware & Test 1.2 \\
\hline $17 a-2$ & 38210 & Failed & $5 / 8^{\prime \prime}$ & Hardware & Test 1.2 \\
\hline $7 a-2$ & 36080 & Failed & $5 / 8^{\prime \prime}$ & Hardware & Test 1.2 \\
\hline $15 a-1$ & 46280 & Failed & $5 / 8^{\prime \prime}$ & Hardware & Test 1.2 \\
\hline $11 a-2$ & 43990 & Intact & $5 / 8^{\prime \prime}$ & Hardware & Test 1.2 \\
\hline $15 a-2$ & 1040 & Intact & $5 / 8^{\prime \prime}$ & Hardware & Test 1.2 \\
\hline $29 a-2$ & Did Not Run & & & & \\
\hline
\end{tabular}




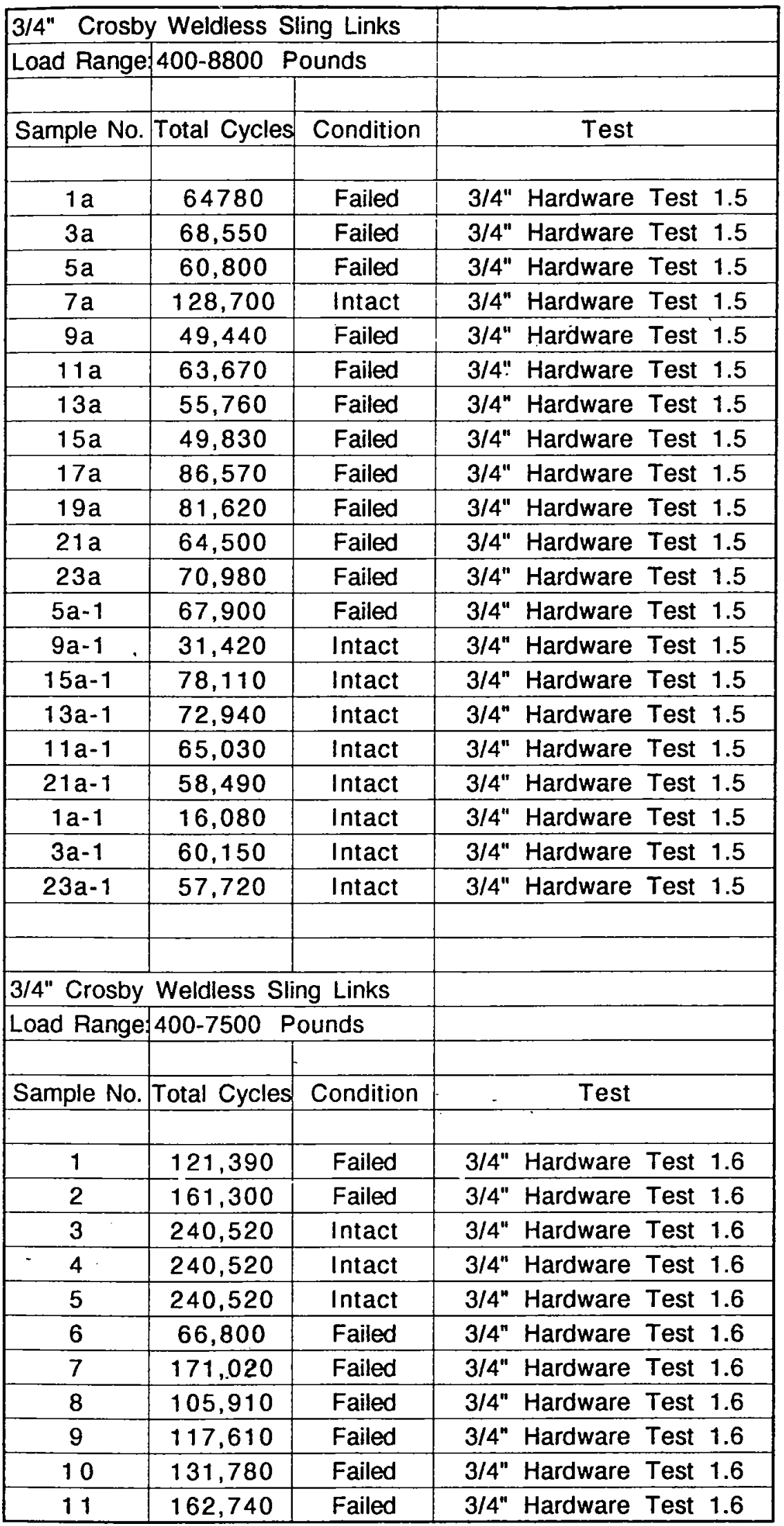




\begin{tabular}{|c|c|c|c|c|c|c|}
\hline 12 & 192,310 & Failed & $3 / 4^{\prime \prime}$ & Hardware & Test & 1.6 \\
\hline 13 & 119,690 & Failed & $3 / 4^{\prime \prime}$ & Hardware & Test & 1.6 \\
\hline 14 & 104,750 & Failed & $3 / 4^{\prime \prime}$ & Hardware & Test & 1.6 \\
\hline 15 & 122,910 & Failed & $3 / 4^{\prime \prime}$ & Hardware & Test & 1.6 \\
\hline 16 & 119,130 & Intact & $3 / 4^{\prime \prime}$ & Hardware & Test & 1.6 \\
\hline 17 & 108,740 & Intact & $3 / 4^{\prime \prime}$ & Hardware & Test & 1.6 \\
\hline 18 & 79,220 & Intact & $3 / 4^{\prime \prime}$ & Hardware & Test & 1.6 \\
\hline 19 & 77,780 & Intact & $3 / 4^{\prime \prime}$ & Hardware & Test & 1.6 \\
\hline 20 & 69,500 & Intact & $3 / 4^{\prime \prime}$ & Hardware & Test & 1.6 \\
\hline 21 & 54,030 & Intact & $3 / 4^{\prime \prime}$ & Hardware & Test & 1.6 \\
\hline 22 & 48210 & Intact & $3 / 4^{\prime \prime}$ & Hardware & Test & 1.6 \\
\hline 23 & 29860 & Intact & $3 / 4^{\prime \prime}$ & Hardware & Test & 1.6 \\
\hline & & & & & & \\
\hline & & & & & & \\
\hline \multicolumn{7}{|c|}{ 3/4" Crosby Weldless Sling Links } \\
\hline \multicolumn{7}{|c|}{ Load Range: $400-10200$ pounds } \\
\hline Sample Na. & Total Cycles & Condition & & Test & & \\
\hline $1 \mathrm{a}$ & 28270 & Failed & $3 / 4^{\prime \prime}$ & Hardware & Test & 1.4 \\
\hline $3 a$ & 40170 & Failed & $3 / 4^{\prime \prime}$ & Hardware & Test & 1.4 \\
\hline $5 a$ & 39360 & Failed & $3 / 4^{\prime \prime}$ & Hardware & Test & 1.4 \\
\hline $7 a$ & 24090 & Failed & $3 / 4^{\prime \prime}$ & Hardware & Test & 1.4 \\
\hline $9 a$ & 37920 & Failed & $3 / 4^{\prime \prime}$ & Hardware & Test & 1.4 \\
\hline $11 \mathrm{a}$ & 43650 & Failed & $3 / 4 "$ & Hardware & Test & 1.4 \\
\hline $7 a-1$ & 26550 & Failed & $3 / 4 "$ & Hardware & Test & 1.4 \\
\hline $1 \mathrm{a}-1$ & 20970 & Failed & $3 / 4^{\prime \prime}$ & Hardware & Test & 1.4 \\
\hline $9 a-1$ & 82270 & Failed & $3 / 4 "$ & Hardware & Test & 1.4 \\
\hline $5 A-1$ & 18760 & Failed & $3 / 4^{\prime \prime}$ & Hardware & Test & 1.4 \\
\hline $3 A-1$ & 10090 & Failed & $3 / 4^{\prime \prime}$ & Hardware & Test & 1.4 \\
\hline $11 \mathrm{~A}-1$ & 20280 & Failed & $3 / 4^{\prime \prime}$ & Hardware & Test & 1.4 \\
\hline $1 A-11$ & 30740 & Failed & $3 / 4^{\prime \prime}$ & Hardware & Test & 1.4 \\
\hline $3 A-2$ & 28596 & Failed & $3 / 4^{\prime \prime}$ & Hardware & Test & 1.4 \\
\hline $7 A-11$ & 24200 & Failed & $3 / 4 "$ & Hardware & Test & 1.4 \\
\hline $7 A-111$ & 49460 & Failed & $3 / 4$ & Hardware & Test & 1.4 \\
\hline $5 A-2$ & 28160 & Failed & $3 / 4^{\prime \prime}$ & Hardware & Test & 1.4 \\
\hline$-11 A-2$ & 24830 & Failed & $3 / 4^{\prime \prime}$ & Hardware & Test & 1.4 \\
\hline $3 A-3$ & 48920 & Failed & $3 / 4^{\prime \prime}$ & Hardware & Test & 1.4 \\
\hline $5 A-3$ & 28800 & Failed & $3 / 4^{\prime \prime}$ & Hardware & Test & 1.4 \\
\hline $11 \mathrm{~A}-3$ & 26560 & Failed & $3 / 4^{\prime \prime}$ & Hardware & Test & 1.4 \\
\hline $5 A-4$ & 41330 & Failed & $3 / 4^{\prime \prime}$ & Hardware & Test & 1.4 \\
\hline $11 \mathrm{~A}-4$ & 33330 & Failed & $3 / 4^{\prime \prime}$ & Hardware & Test & 1.4 \\
\hline $9 A-2$ & 28170 & Failed & $3 / 4^{\prime \prime}$ & Hardware & Test & 1.4 \\
\hline $7 A-4$ & 41720 & Failed & $3 / 4^{\prime \prime}$ & Hardware & Test & 1.4 \\
\hline
\end{tabular}




\begin{tabular}{|c|c|c|c|c|}
\hline $3 \mathrm{~A}-4$ & 26290 & Failed & $3 / 4^{\prime \prime}$ & Hardware Test 1.4 \\
\hline $1 \mathrm{~A}-3$ & 56560 & Failed & $3 / 4^{\prime \prime}$ & Hardware Test 1.4 \\
\hline $9 \mathrm{~A}-3$ & 27700 & Failed & $3 / 4^{\prime \prime}$ & Hardware Test 1.4 \\
\hline $11 \mathrm{~A}-5$ & 38530 & Failed & $3 / 4^{\prime \prime}$ & Hardware Test 1.4 \\
\hline $3 \mathrm{~A}-5$ & 25870 & Failed & $3 / 4^{\prime \prime}$ & Hardware Test 1.4 \\
\hline $5 \mathrm{~A}-5$ & 35530 & Failed & $3 / 4^{\prime \prime}$ & Hardware Test 1.4 \\
\hline $7 \mathrm{~A}-5$ & 34410 & Failed & $3 / 4^{\prime \prime}$ & Hardware Test 1.4 \\
\hline $9 \mathrm{~A}-4$ & 29380 & Failed & $3 / 4^{\prime \prime}$ & Hardware Test 1.4 \\
\hline $3 \mathrm{~A}-6$ & 45370 & Failed & $3 / 4^{\prime \prime}$ & Hardware Test 1.4 \\
\hline $1 \mathrm{~A}-4$ & 31570 & Failed & $3 / 4^{\prime \prime}$ & Hardware Test 1.4 \\
\hline $5 \mathrm{~A}-6$ & 31020 & Failed & $3 / 4^{\prime \prime}$ & Hardware Test 1.4 \\
\hline $7 \mathrm{~A}-6$ & 57610 & Failed & $3 / 4^{\prime \prime}$ & Hardware Test 1.4 \\
\hline $9 \mathrm{~A}-5$ & 25250 & Failed & $3 / 4^{\prime \prime}$ & Hardware Test 1.4 \\
\hline $3 \mathrm{~A}-7$ & 24080 & Failed & $3 / 4^{\prime \prime}$ & Hardware Test 1.4 \\
\hline $11 \mathrm{a}-6$ & 70860 & Intact & $3 / 4^{\prime \prime}$ & Hardware Test 1.4 \\
\hline $5 \mathrm{a}-7$ & 35080 & Intact & $3 / 4^{\prime \prime}$ & Hardware Test 1.4 \\
\hline $1 \mathrm{a}-5$ & 40810 & Intact & $3 / 4^{\prime \prime}$ & Hardware Test 1.4 \\
\hline $9 \mathrm{a}-6$ & 27350 & Intact & $3 / 4^{\prime \prime}$ & Hardware Test 1.4 \\
\hline $3 \mathrm{a}-8$ & 8660 & Intact & $3 / 4^{\prime \prime}$ & Hardware Test 1.4 \\
\hline $1 \mathrm{~A}-2$ & 27030 & Failed & $3 / 4^{\prime \prime}$ & Hardware Test 1.4 \\
\hline & & & & \\
\hline
\end{tabular}




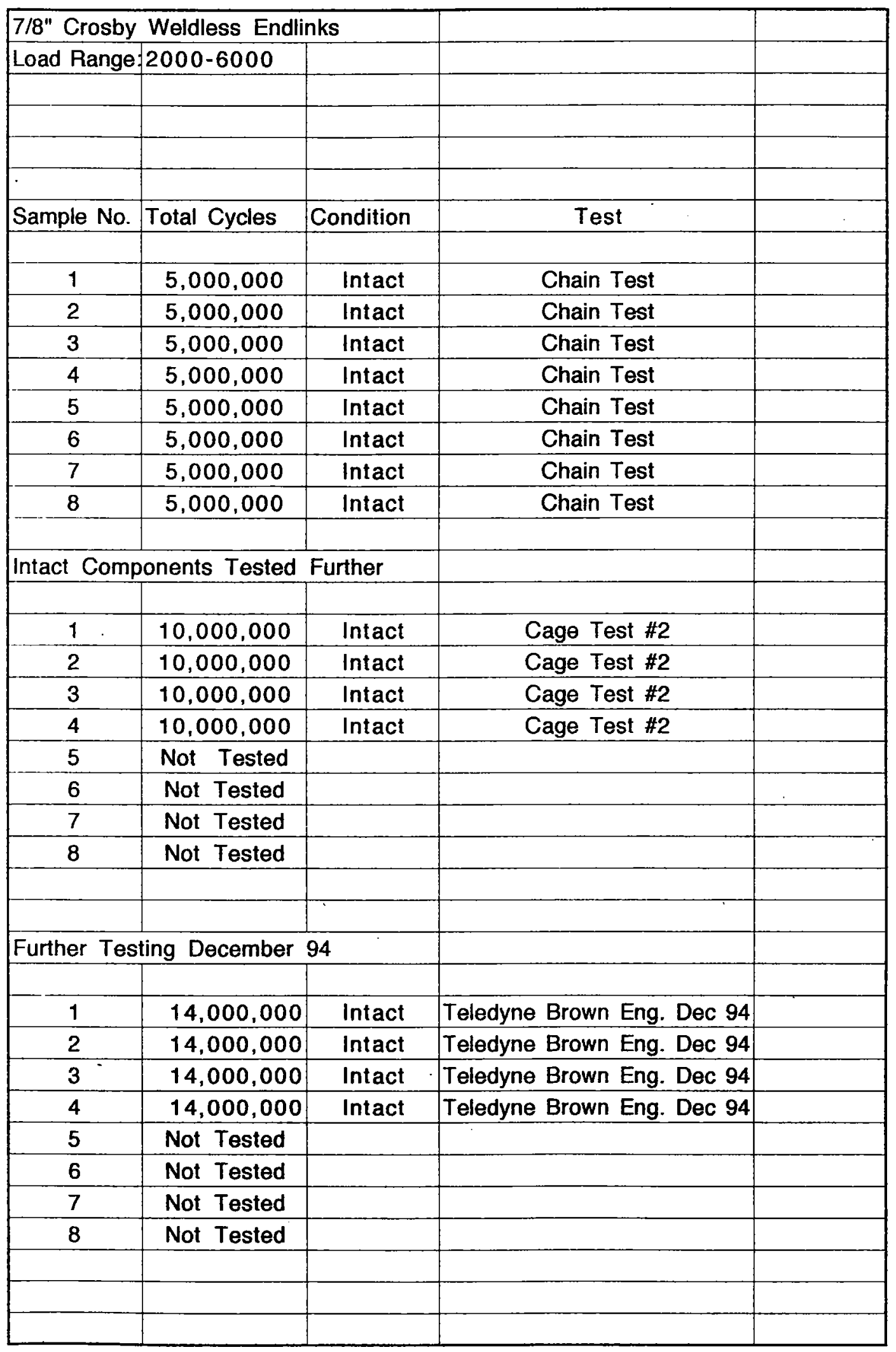


$3 / 4^{n}$ Chain

\begin{tabular}{|c|c|c|c|c|}
\hline 3/4" System 3 Proof Coil Chain & & \\
\hline & & & & \\
\hline & & & & \\
\hline & & & & \\
\hline & & & & \\
\hline Load Range:2000-6000 & & & \\
\hline & & & & \\
\hline 1 & $5,000,000$ & Intact & Chain Test & \\
\hline 2 & $5,000,000$ & Intact & Chain Test & \\
\hline 3 & $5,000,000$ & Intact & Chain Test & \\
\hline 4 & $5,000,000$ & Intact & Chain Test & \\
\hline & & & & \\
\hline & & & & \\
\hline
\end{tabular}


VMCM Cages

\begin{tabular}{|c|c|c|c|}
\hline VMCM Cages with 3/4" Cage Rods & \\
\hline & & & \\
\hline & & & \\
\hline Load Range: $400-6800$ Pounds & \\
\hline & & & Test \\
\hline Cage 1 & 351,240 & Failed & Cage Test \#1 \\
\hline Cage 2 & 967,080 & Failed & Cage Test \#1 \\
\hline & & & \\
\hline & & & \\
\hline & & & \\
\hline & & & \\
\hline VMCM Cages with 3/4" Cage Rods and Gussets \\
\hline Load Range: & $2000-6000$ Pounds & \\
\hline & & & \\
\hline Sample No. & Total Cycles & Condition & \\
\hline & & & Test \\
\hline Cage 3 & $5,000,000$ & Intact & Cage Test\#2 \\
\hline Cage 4 & $5,000,000$ & Intact & Cage Test \#2 \\
\hline & & & \\
\hline & & & \\
\hline
\end{tabular}


7/16" Wire Rope

\begin{tabular}{|c|c|c|c|}
\hline 7/16" Wire & Rope & & \\
\hline Load Range: & $400-6800 \mathrm{pou}$ & inds & \\
\hline & & & \\
\hline & & & \\
\hline & & & \\
\hline Sample No. & Total Cycles & Condition & Test \\
\hline 1 & 198,850 & Failed & Wire Test \#1 \\
\hline 2 & 223,940 & Failed & Wire Test $\# 1$ \\
\hline 3 & 304,870 & Failed & Wire Test \#1 \\
\hline 4 & 344,320 & Failed & Wire Test \#1 \\
\hline & & & \\
\hline & & & \\
\hline 7/16" Wire & Rope & & \\
\hline Load Range: & $2000-6000 \mathrm{po}$ & unds & \\
\hline & & & \\
\hline Sample No. & Total Cycles & Condition & Test \\
\hline 1 & 995,470 & Failed & Wire Test \#2 \\
\hline 2 & $2,594,840$ & Failed & Wire Test \#2 \\
\hline 3 & $2,594,840$ & Intact & Wire Test \#2 \\
\hline 4 & $2,594,840$ & Intact & Wire Test \#2 \\
\hline & & & \\
\hline & & & \\
\hline
\end{tabular}




\section{DOCUMENT LIBRARY}

Distribution List for Technical Report Exchange - May 1995

University of California, San Diego

SIO Library 0175C

9500 Gilman Drive

La Jolla, CA 92093-0175

Hancock Library of Biology \& Oceanography

Alan Hancock Laboratory

University of Southern California

University Park

Los Angeles, CA 90089-0371

Gifts \& Exchanges

Library

Bedford Institute of Oceanography

P.O. Box 1006

Dartmouth, NS, B2Y 4A2, CANADA

Commander

International Ice Patrol

1082 Shennecossett Road

Groton, CT 06340-6095

V()AA/EDIS Miami Library Center

4301 Rickenbacker Causeway

Miami, FL 33149

Research Library

U.S. Army Corps of Engineers

Waterways Experiment Station

3909 Halls Ferry Road

Vicksburg, MS 39180-6199

Institute of Geophysics

University of Hawaii

Library Room 252

2525 Correa Road

Honolulu, HI 96822

Marine Resources Information Center

Building E38-320

MIT

Cambridge, MA 02139

Library

Lamont-Doherty Geological Observatory

Columbia University

Palisades, NY z10964

Library

Serials Department

Oregon State University

Corvallis, OR 97331

Pell Marine Science Library

University of Rhode Island

Narragansett Bay Campus

Narragansett, RI 02882
Working Collection

Texas A\&M University

Dept. of Oceanography

College Station, TX 77843

Fisheries-Oceanography Library 151 Oceanography Teaching Bldg.

University of Washington

Seattle, WA 98195

Library

R.S.M.A.S.

University of Miami

4600 Rickenbacker Causeway

Miami, FL 33149

Maury Oceanographic Library

Naval Oceanographic Office

Building 1003 South

1002 Balch Blvd.

Stennis Space Center, MS, 39522-5001

Library

Institute of Ocean Sciences

P.O. Box 6000

Sidney, B.C. V8L 4B2

CANADA

Library

Institute of Oceanographic Sciences

Deacon Laboratory

Wormley, Godalming

Surrey GU8 5UB

UNITED KINGDOM

The Librarian

CSIRO Marine Laboratories

G.P.O. Box 1538

Hobart, Tasmania

AUSTRALIA 7001

Library

Proudman Oceanographic Laboratory

Bidston Observatory

Birkenhead

Merseyside L43 7 RA

UNITED KINGDOM

IFREMER

Centre de Brest

Service Documentation - Publications BP 7029280 PLOUZANE

FRANCE 


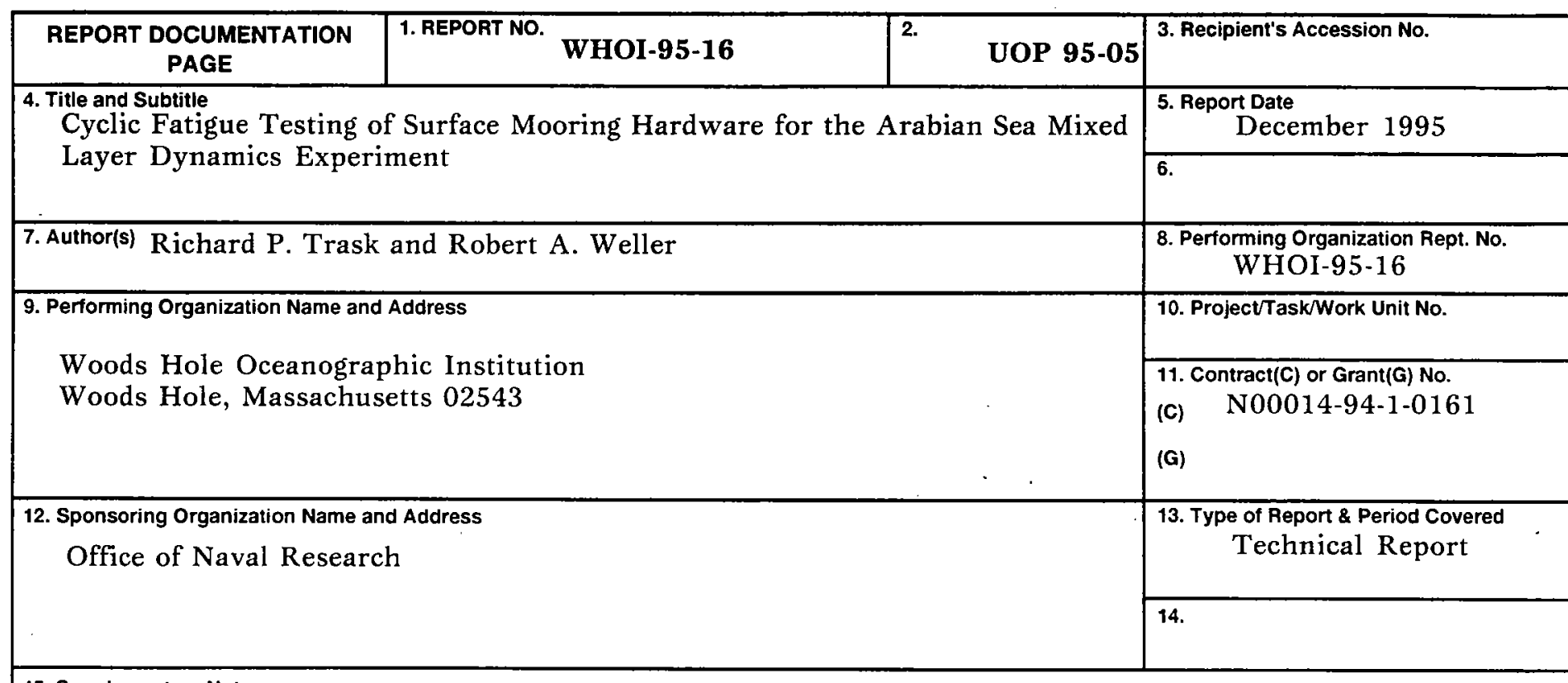

15. Supplementary Notes

This report should be cited as: Woods Hole Oceanog. Inst. Tech. Rept., WHOI-95-16.

16. Abstract (Limit: 200 words)

The Arabian Sea is strongly forced by monsoon winds. Surface moorings deployed in the Arabian Sea are exposed to high winds and large waves. The waves, generated by strong wind events, impose a dynamic load on all mooring components. The dynamic cycling of mooring components can be so severe that ultimate strength considerations are superseded by the fatigue properties of the standard hardware components.

Concerns about all in-line mooring components and their fatigue endurance dictated the need for an independent series of cyclic fatigue tests. The components tested included shackles of various sizes and configurations, wire rope, instrument cages, chain, and a variety of interconnecting links such as weldless sling links and end links. The information gained from these tests was used in the design of the surface moorings deployed in the Arabian Sea by the Upper Ocean Processes group of the Woods Hole Oceanographic Institution.

The results of the cyclic fatigue tests conducted in support of the Arabian Sea surface mooring design effort are presented in this report. Recommendations are made with regard to all in-line components for surface moorings where dynamic conditions might be encountered for extended periods. The fatigue test results from shackles, and sling links were compiled to generate an $\mathbf{S} / \mathbf{N}$ diagram where the cyclic stress amplitude is plotted versus the number of cycles to failure. In addition, the wire rope test results were compiled with historical wire rope data from US steel to generate a $S / N$ diagram for torque balanced $3 \times 19$ wire rope. These results can be used in conjunction with future design efforts.

17. Document Analysis a. Descriptors

cyclic fatigue

mooring hardware

Arabian Sea

b. Identifiers/Open-Ended Terms

c. COSATI Field/Group

18. Availability Statement

Approved for public release; distribution unlimited.

\begin{tabular}{|l|l|}
\hline $\begin{array}{c}\text { 19. Security Class (This Report) } \\
\text { UNCLASSIFIED }\end{array}$ & $\begin{array}{c}\text { 21. No. of Pages } \\
63\end{array}$ \\
\hline 20. Security Class (This Page) & 22. Price \\
\hline
\end{tabular}

